Document downloaded from:

http://hdl.handle.net/10251/71420

This paper must be cited as:

De Rosa, M.; Ruiz Calvo, F.; Corberán Salvador, JM.; Montagud Montalvá, Cl.; Tagliafico, L. (2015). A novel TRNSYS type for short-term borehole heat exchanger simulation: B2G model. Energy Conversion and Management. 100:347-357.

doi:10.1016/j.enconman.2015.05.021

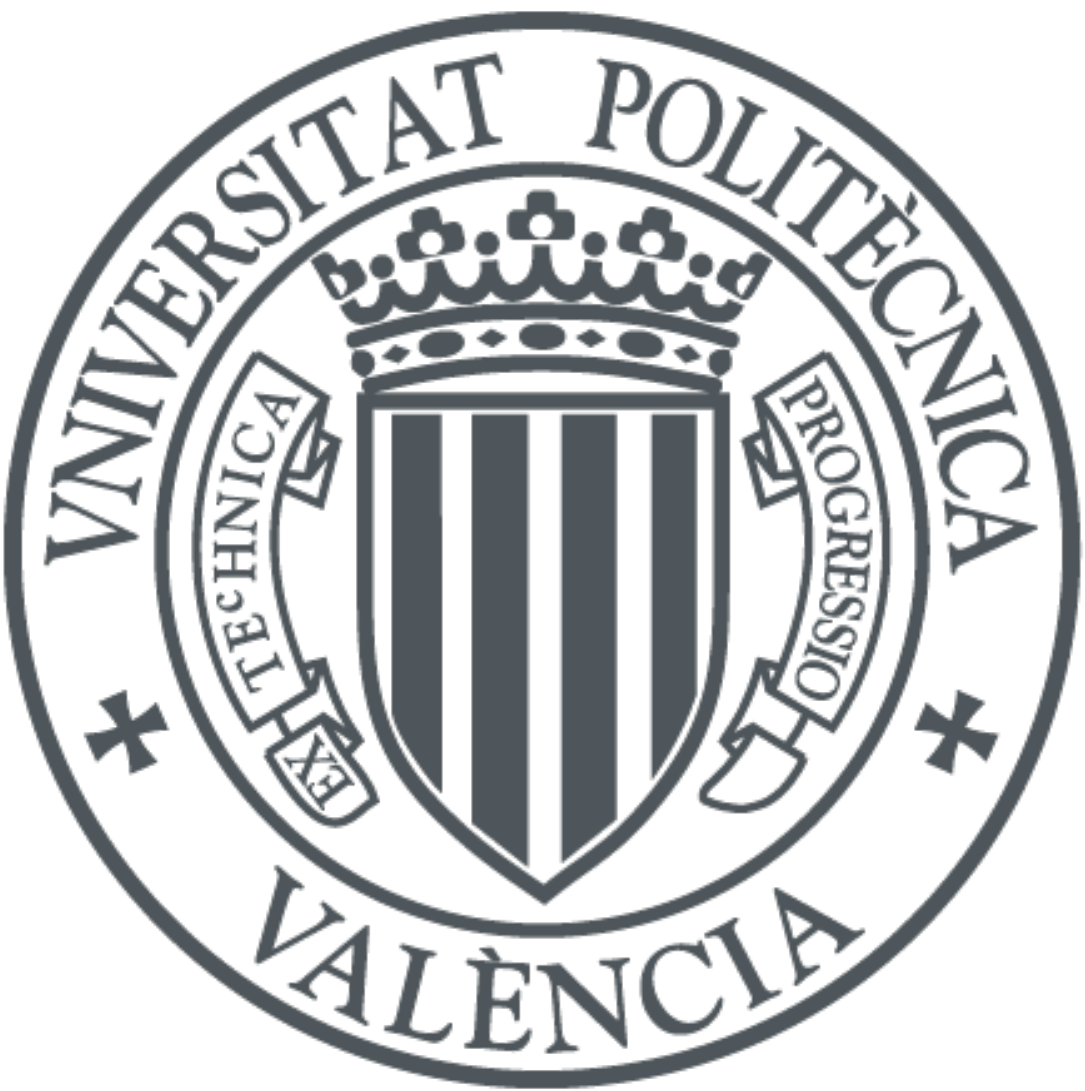

The final publication is available at

http://dx.doi.org/10.1016/j.enconman.2015.05.021

Copyright Elsevier

Additional Information 


\section{"A novel TRNSYS type for short-term borehole beat exchanger simulation: B2G model"}

by

Mattia De Rosa ${ }^{*}$, Félix Ruiz Calvo ${ }^{\mathrm{b}}$, José M. Corberán ${ }^{\mathrm{b}}$, Carla Montagud ${ }^{\mathrm{b}}$, Luca A. Tagliafico

a DIME/TEC - Division of Thermal Energy and Environmental Conditioning, University of Genoa, via All'Opera Pia 15/ A 16145, Genoa, Italy.

b Instituto de Ingeniería Energética, Universitat Politécnica de Valéncia. Camino de Vera sn 46022 Valencia, Spain.

Contents lists available at ScienceDirect

Energy Conversion and Management

ELSEVIER

journal homepage: www.elsevier.com/locate/enconman

To be published in Energy Conversion and Management

DOI: $10.1016 /$ j.enconman.2015.05.021

\section{Highlights}

A novel dynamic Borehole Heat Exchanger model is presented.

Theoretical approach for model parameters calculation is described.

The short-term model is validated against experimental data of a real GSHP.

Strong dynamic conditions due to the ON-OFF regulation are investigated.

$\left(^{*}\right)$ corresponding author - Dr. Mattia De Rosa email: mattia.derosa@unige.it; m_derosa@hotmail.it 


\title{
A novel TRNSYS type for short-term borehole heat exchanger simulation: $\mathrm{B} 2 \mathrm{G}$ model
}

\author{
Mattia De Rosa ${ }^{\mathrm{a}, *}$, Félix Ruiz-Calvo $^{\mathrm{b}}$, José M. Corberán ${ }^{\mathrm{b}}$, Carla \\ Montagud $^{\mathrm{b}}$, Luca A. Tagliafico ${ }^{\mathrm{a}}$ \\ ${ }^{a}$ DIME/TEC - Division of Thermal Energy and Environmental Conditioning, \\ University of Genova. Via dell'Opera Pia 16145 Genova, Italy. Phone: \\ +39-010-3532578. Fax: +39-010-311870 \\ ${ }^{b}$ Instituto de Ingeniería Energética, Universitat Politècnica de València. \\ Camino de Vera sn 46022 Valencia, Spain. Phone: +34-96-3879910. Fax: \\ $+34-963877272$
}

\begin{abstract}
Models of ground source heat pump (GSHP) systems are used as an aid for the correct design and optimization of the system. For this purpose, it is necessary to develop models which correctly reproduce the dynamic thermal behavior of each component in a short-term basis. Since the borehole heat exchanger (BHE) is one of the main components, special attention should be paid to ensuring a good accuracy on the prediction of the short-term response of the boreholes. The BHE models found in literature which are suitable for short-term simulations usually present high computational costs. In this work, a novel TRNSYS type implementing a borehole-to-ground (B2G) model, developed for modeling the short-term dynamic performance of a $\mathrm{BHE}$ with low computational cost, is presented. The model has been validated against experimental data from a GSHP system located at Universitat Politècnica de València, Spain. Validation results show the ability of the model to reproduce the short-term behavior of the borehole, both for a step-test and under normal operating conditions.
\end{abstract}

Keywords: ground source heat pump, borehole heat exchanger, heating and cooling systems, dynamic modeling

${ }^{*}$ Corresponding author at: DIME/TEC - Division of Thermal Energy and Environmental Conditioning, University of Genova. Via dell'Opera Pia 16145 Genova, Italy.

Email addresses: mattia.derosa@unige.it; m_derosa@hotmail.it (Mattia De Rosa), fliruica@etsii.upv.es (Félix Ruiz-Calvo), corberan@upvnet.upv.es (José M. Corberán), carmonmo@iie.upv.es (Carla Montagud), tgl@ditec.unige.it (Luca A. Tagliafico)

Preprint submitted to Energy Conversion and Management

April 18, 2015

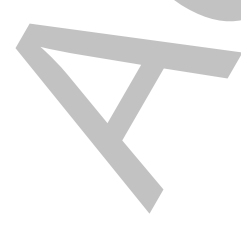




\section{Introduction}

2

3

4

5

6

7

8

9

10

11

Geothermal energy systems have been recognized as being among the most efficient and comfortable heating and cooling systems currently available by the U.S. Environmental Protection Agency [1], presenting several advantages respect to air source heat pumps [2]. Ground source heat pumps (GSHP) represent one of the common available and profitable geothermal systems, using the ground as a heat source in winter and as a heat sink in summer. Generally, the heat exchange takes place in a ground source heat exchanger (GSHE) and different configurations can be adopted. Among those, one of the most commonly used is the vertical borehole field, consisting on a certain number of boreholes drilled in the ground, inside which the heat carrier fluid exchanges heat with the surrounding ground, depending on the operating conditions.

Ever since the first GSHPs were installed, lots of research works have been addressed to the analysis and modeling of this kind of installations. Recent works are performed in order to investigate the thermodynamic aspects [3, 4], the geometries and the system thermal performance [5, 6, 7, 8, 9], and involving numerical issues $[10,11,12]$. An interesting overall review on these systems with a comparison with other technologies can be found in [13].

In this context, obtaining an accurate model for the GSHE has been one of the main focuses of research through the last years, in which several approaches with different characteristics have been considered (an accurate review on the different models is presented by Yang et al. [14]). Some of them are discussed in the following, focusing on one of the most common borehole configurations: vertical boreholes with U tubes. 
Eskilson [15] proposed a steady state model combining analytical and numerical solution techniques. It is based on the use of non-dimensional temperature response factors, called g-functions, that represent the temperature response to a constant heat injection pulse, for a certain time step. Then, the actual thermal load is divided into a series of step loads and the temperature response of the borehole is obtained by superimposing the single response at each step. Another version of this approach consists in using an exponential integral function, as presented in [16]. Eskilson obtained the g-function through a two-dimensional numerical calculation: with this approach, it is possible to calculate the borehole temperature in time steps greater than $5 r_{b} / \alpha$, which results in 3 to 6 hours for a typical borehole. In [17], the g-functions calculated by Eskilson are extended to shorter time steps. After calculating the borehole temperature, it is possible to obtain the outlet fluid temperature by means of the borehole resistance and of the entering fluid temperature. The g-function is widely used in simulation and design software, such as GLHEPRO [18] or EED [19], and it has been improved in the last years, for example, generating numerically g-functions for specific GSHE geometries, as in [20]. The temporal superposition method is also at the base of the BHE/design procedure presented by Deerman and Kavanaugh [21] and later refined by Kavanaugh and Rafferty [22] which is adopted as standard in the Ashrae Handbook [23]. A useful description of this model and a recent calculation procedure to calculate proper response factor are presented in [24]. Recently, Koohi-Fayegh and Rosen [25] proposed a semi-analytical approach to couple a model outside the borehole, based on the transient finite line-source model, with one inside the borehole which assumes a steady-state heat conduction. 
Another approach to numerically describe a vertical borehole is the thermal network model, in which the borehole and the surrounding ground are represented as a series of temperature nodes connected by thermal resistances. In order to model the thermal inertia, thermal capacitances are added to the temperature nodes [26]. The basic thermal network is the delta network, with one node on each pipe of the $U$ tube and one node at the borehole wall [27] (Figure 11). Many improvements have been made to the delta network, usually adding more nodes to the network, as in [28, 29] and [30], or dividing the borehole into two or more areas, depending on the internal borehole geometries [31]. The thermal network approach can also be used for modelling the behavior of the ground around the borehole, from the undisturbed ground temperature to the borehole wall. However, if a high accuracy is desired, the network has to be very fine, increasing the number of temperature nodes, which results in a greater number of differential equations that must be solved causing a longer simulation time needed. The borehole thermal resistance is used in the thermal network approach, since it represents the resistance between the pipes and the borehole wall. This resistance can be experimentally obtained, as described in [31], or it can be calculated analytically. Furthermore, Lamarche et al. [31] present an exhaustive review of different methods to obtain the borehole resistance starting from the borehole geometry and from the thermal characteristics of fluid, pipes and grout. In Sharqawy et al. [32], a correlation for the borehole resistance is obtained numerically and compared with approximate analytical solutions.

Finally, the finite elements model (FEM) represents one of the more detailed models available in literature (some examples can be found in [33, 


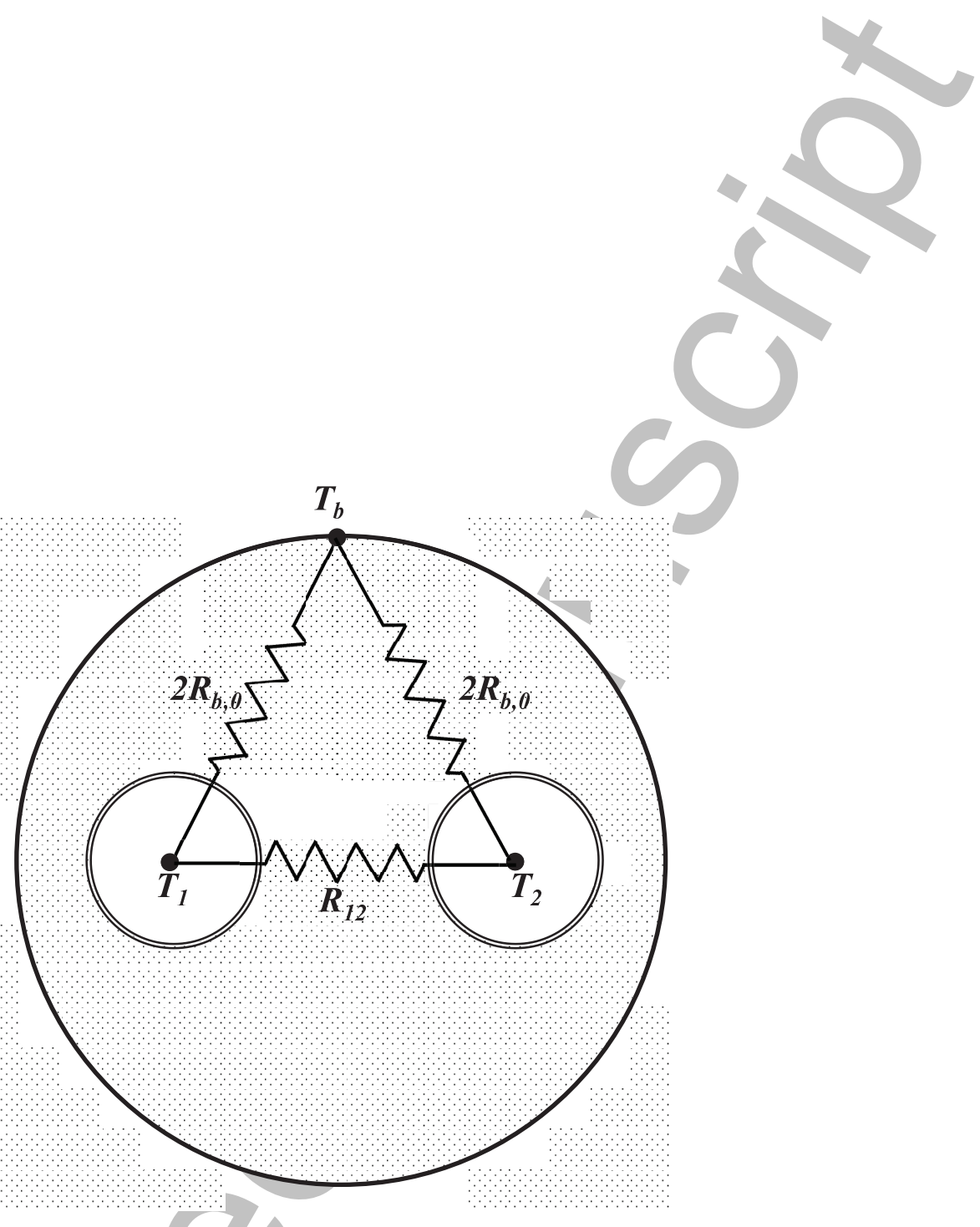

Figure 1: Standard steady state delta network [27]. 
34], [35], and [36]), which allows to obtain the most accurate results despite a high computational cost, due to the more detailed discretization of the borehole and of the surrounding ground. Therefore, FEM models are usually assumed as a reference for validation of simpler models that can provide faster simulation results, although not being so accurate.

Several other numerical models have been developed in the last years (as, e.g., [37, 38] ) adopting different approaches (see [39, 40]). Most of them can only be used to simulate the borehole thermal performance for long time steps, usually greater than an hour without reproducing the short-term dynamic behavior. However, the dynamic short-term behavior becomes a relevant issue, especially considering that GSHEs are generally integrated in other complex systems, in which the short-term regulation criteria assume an important role in the energy performance of the whole system. For these reasons, steady state models or dynamic models with higher timescale are not useful for analyzing and optimizing these complex systems. In this context, more complex models, such as FEM, in which a detailed description of the heat transfer phenomenon inside the borehole is provided are not convenient due to their high computational costs.

A complete model of a GSHP system for heating and cooling in an office building located at the Universitat Politènica de València (UPVLC), in Spain, has recently been developed by the authors [41], using TRNSYS simulation software [42]. The system operation is based on an ON/OFF control, commonly used in this kind of installations. The characteristic water temperature evolution due to the $\mathrm{ON} / \mathrm{OFF}$ cycling of the heat pump has a great influence in the design and optimization of the installation. In this context, due to the low characteristic time (minutes) for the different 
system components (tank, pipes, heat pump, etc.), it is necessary to find a GSHE model that is able to reproduce the thermal behavior of the boreholes for very short heat injection/extraction periods. Furthemore, since it is to be embedded in a global complex model developed in the TRNSYS environment, a low computational time becomes key for modeling the GSHE. Therefore, FEMs cannot be used for the purpose of this work. On the other hand, steady state models are neither appropriate for this aim, since they are not meant to predict short-term behavior.

At the UPVLC GSHP installation, the duration of the ON periods of the heat pump is about 10 minutes, although it depends on the thermal load and the implemented control algorithm. The system is switched on normally 15 hours a day, but the total heat injection/extraction period may vary from 1.5 to 10 hours, depending on the thermal load for each day. Due to this particular operation, in the GSHE, the system thermal load may only affect a reduced volume around the boreholes, in the short-term. Therefore, the thermal response of a borehole for an operational day can be modeled just taking into account the ground near the borehole. The novelty of the approach proposed in this paper consists in using two separate models for the local and global solution calculation. Thus, the short-term and long-term simulation are decoupled and faster models can be used on each side. On one hand, the short-term model only takes into account the ground volume directly affected by the heat injection/extraction period of an operational day. This model should be able to reproduce the instantaneous response of the BHE due to the ON-OFF operation, for a total operating time of 15 hours. For this purpose, the model uses the initial ground temperature of each day as a starting point of the calculations. Therefore, a long-term 
model able to calculate the initial ground temperature for each day, taking into account the thermal load of the previous one, is required. The total computational cost of the global model resulting from the combination of both short and long-term models is reduced, since the long-term response of the ground is calculated on a daily basis, instead of being calculated at every time-step.

The aim of the present work is to present a new TRNSYS type specially developed for modelling the short-term behavior of a borehole heat exchanger (BHE). The TRNSYS type implements a novel dynamic model, called borehole-to-ground (B2G) model, which is able to simulate the shortterm behavior of a single U-tube borehole over a period of at least 10-15 hours. This short-term model can be coupled with a standard steady-state long-term model, such as the g-function, in order to take into account the long-term behavior of the ground, e.g. correcting the initial ground temperature for each simulated day. B2G model was initially presented in [11], where it was validated against experimental data from a BHE located in Stockholm, Sweden. Moreover, a comparison of the performance of B2G with that of a standard steady-state model can be found in [43]. In particular, B2G model was compared to the one already programmed in the TRNSYS software (type 557), which implements the Duct Ground Heat Storage Model (DST) developed by Hellström [44]. As reported in [43], DST model is a useful model able to produce a good estimation of the ground temperature at the boreholes along the years. Nevertheless, its main limitation is the steady-state assumption and the neglect of the advection effect in the outlet water temperature calculation procedure, which could affect strongly the performance of the model for very short time steps like the ones existing 
in $\mathrm{ON} / \mathrm{OFF}$ GSHP systems.

The aim of the present paper is to extend the validation of $\mathrm{B} 2 \mathrm{G}$ model to stronger dynamic conditions which occur typically with ON/OFF regulation criteria. A detailed description of the model equations and procedures is reported in 2.1. The validation is performed comparing the numerical results provided by $\mathrm{B} 2 \mathrm{G}$ against experimental measurements from GeoCool plant, installed at Universitat Politècnica de València [45], which operates under an $\mathrm{ON} / \mathrm{OFF}$ control algorithm, as described in section 3.1. In particular, $\mathrm{B} 2 \mathrm{G}$ model is validated considering two different operating conditions: (i) a step-test in cooling mode and (ii) during standard operating mode in two different typical days, one for heating mode and one for cooling mode.

\section{B2G model}

\subsection{B2G model description}

Starting from previous works [28, 29, 30, 31, 38], B2G dynamic numerical model was developed and tested in order to reproduce the behavior of a single U-tube in a short-term scale. B2G model was first presented in RuizCalvo et al. [11]. As stated in section 1, the model is focused on the short-term behavior prediction. Therefore, it takes into account only the BHE itself and the portion of its surrounding ground that is directly affected during the heat injection period considered. A detailed description of the B2G model is provided below, while a schematic figure of the calculation procedure is shown in Figure 2.

B2G model is based on a 2D thermal network model coupled with a vertical discretization of the entire domain (Figure 3b): at each z-depth, the two-dimensional thermal network (Figure [3a) describes the heat transfer 


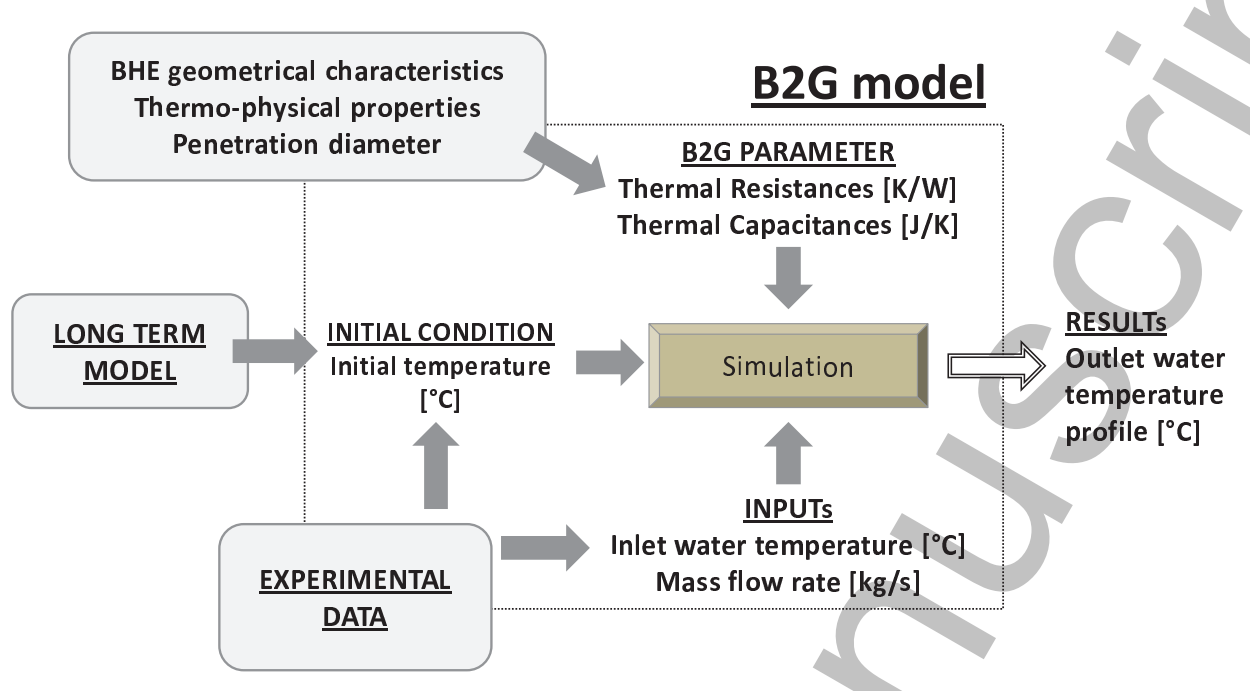

Figure 2: Calculation procedure of $\mathrm{B} 2 \mathrm{G}$ model

a)

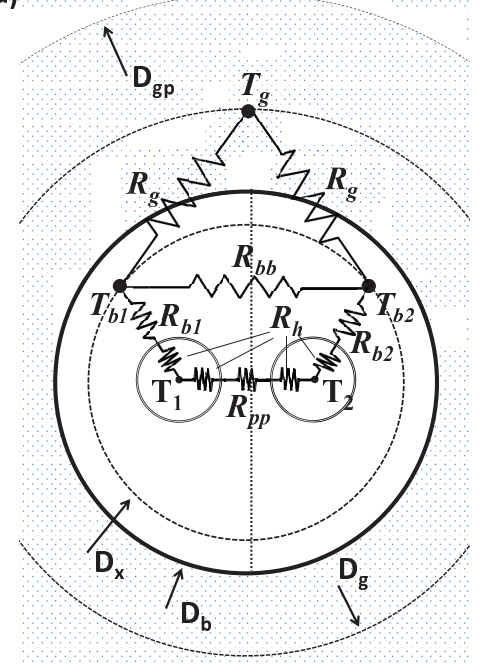

b)

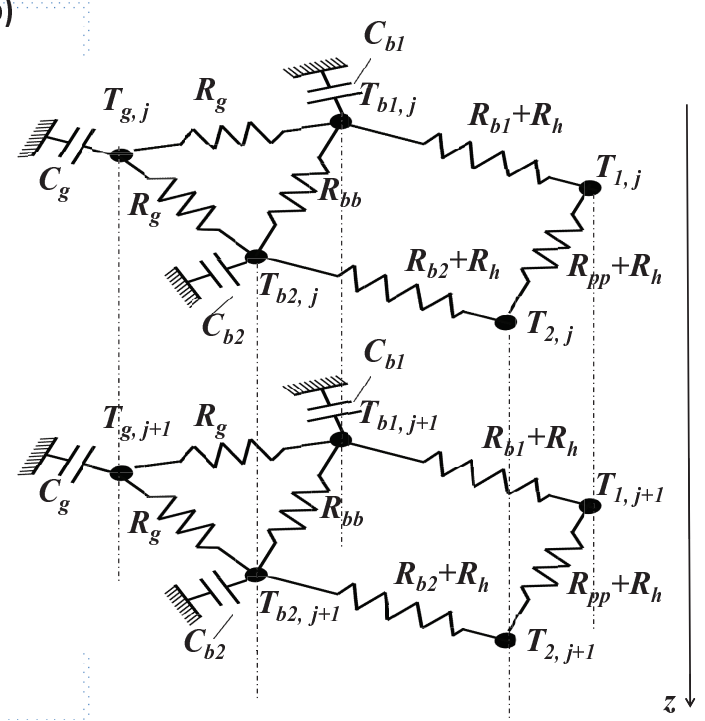

Figure 3: Thermal network model adopted in the present work: a) 2D model; b) 3D model. 
190

between temperature nodes, in which thermal capacitances are lumped, by using thermal resistances. The grout inside the borehole is modeled considering two different regions, as shown in Figure $\underline{3}$ a, resulting in two different borehole nodes [31] with a lumped thermal capacitance (the position of these nodes is discussed in section 2.2). Neglecting vertical conduction, the energy balance equations corresponding to the different nodes of the thermal network correspond to Eqs. 1 to 5 .

$$
\frac{\partial T_{1}(z)}{\partial t}=-v \frac{\partial T_{1}(z)}{\partial z}-\frac{1}{c_{f}}\left(\frac{T_{1}(z)-T_{b 1}(z)}{R_{b 1}}+\frac{T_{1}(z)-T_{2}(z)}{R_{p p}}\right)
$$

$$
\begin{gathered}
\frac{\partial T_{2}(z)}{\partial t}=-v \frac{\partial T_{2}(z)}{\partial z}-\frac{1}{c_{f}}\left(\frac{T_{2}(z)-T_{b 2}(z)}{R_{b 2}}-\frac{T_{1}(z)-T_{2}(z)}{R_{p p}}\right) \\
c_{b 1} \frac{\partial T_{b 1}(z)}{\partial t}=\frac{T_{1}(z)-T_{b 1}(z)}{R_{b 1}}+\frac{T_{b 1}(z)-T_{b 2}(z)}{R_{b b}}-\frac{T_{b 1}(z)-T_{g}(z)}{R_{g}}
\end{gathered}
$$

$$
\begin{gathered}
c_{b 2} \frac{\partial T_{b 2}(z)}{\partial t}=\frac{T_{2}(z)-T_{b 2}(z)}{R_{b 1}}-\frac{T_{b 1}(z)-T_{b 2}(z)}{R_{b b}}-\frac{T_{b 2}(z)-T_{g}(z)}{R_{g}} \\
c_{g} \frac{\partial T_{g}(z)}{\partial t}=\frac{T_{b 1}(z)-T_{g}(z)}{R_{g}}+\frac{T_{b 2}(z)-T_{g}(z)}{R_{g}}
\end{gathered}
$$

For the fluid nodes, the advection in vertical direction has been taken into account in the transient energy balance equation (Eqs. 1 and 2).

The entire model consists of a system of ordinary differential equations, with five thermal capacitances and six thermal resistances at each z-depth (5C6R-n model, where $\mathrm{n}$ is the number of the nodes), which can be solved using standard numerical procedures as described in [11]. The thermal network configuration considered for the B2G model has been chosen in 
order to accomplish the two main aims of the model: reducing the number

of parameters as much as possible while ensuring a good accuracy of the model for short-time response prediction.

\subsection{Parameter calculation}

For a given borehole, where the geometrical characteristics and thermophysical properties are known, it is possible to determine the borehole capacitances and resistances for the model. This section presents the final equations that allow to calculate the parameters of the B2G model, as presented in [11].

\subsubsection{Grout nodes}

Considering each grout zone, the thermal capacitances $C_{b 1}$ and $C_{b 2}$ can be calculated as follows:

$$
C_{b 1}=C_{b 2}=\mathrm{d} z \cdot\left(\frac{S_{b}}{2} c_{b}+S_{p} c_{p}\right) \approx \mathrm{d} z \cdot \frac{S_{b}}{2} c_{b}
$$

$$
S_{b}=\frac{\pi}{4}\left(D_{b}^{2}-2 D_{p, e}^{2}\right)
$$

where $S_{b}$ is the borehole section neglecting the pipes, $\mathrm{d} z$ is the node length and $c_{b}$ is the grout volumetric heat capacity. Since the thermal capacitance of the pipe walls is small, compared to that of the grout, the term $S_{p} c_{p}$ is neglected in equation 6.

Figure 4 shows the different steps that have been carried out for the thermal resistances determination.

The thermal resistances between the grout and pipe nodes depend on the overall borehole thermal resistance $R_{B H E}$ (Figure $4 \mathrm{a}$ ), usually determined by experimental tests. Generally, it is possible to divide the global borehole 


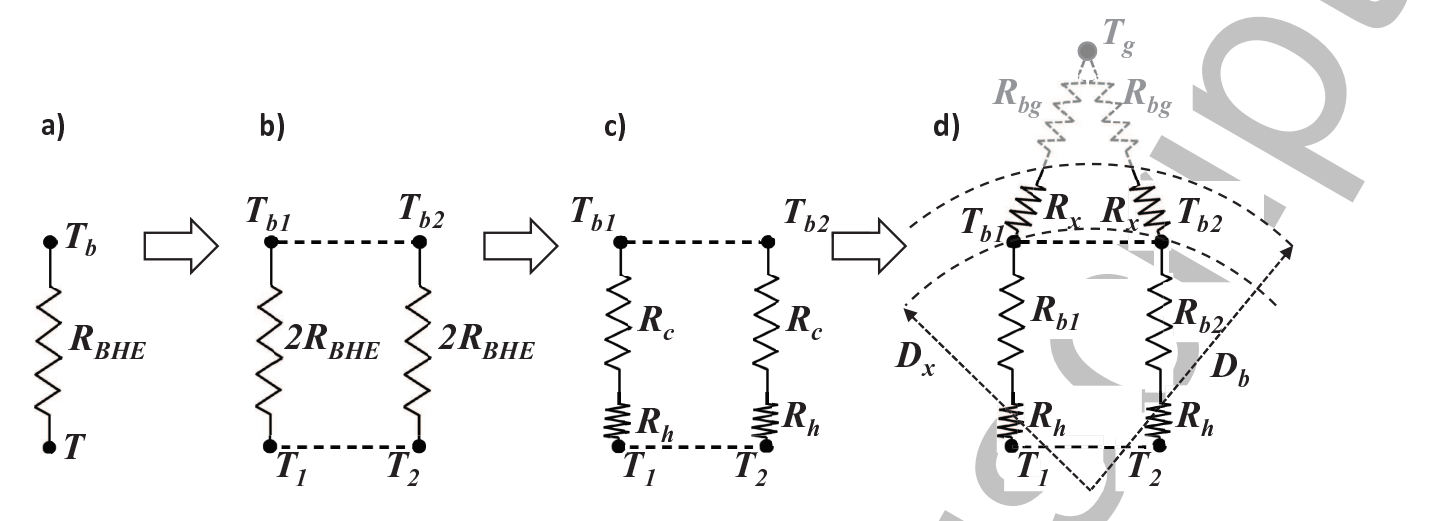

Figure 4: Thermal resistances definition steps: a) borehole resistance, b) parallel borehole resistances, c) convective and conductive resistances, d) final resistances configuration.

thermal resistance $R_{B H E}$ into two thermal parallel resistances connecting each pipe with the corresponding grout zone (Figure $4 \mathrm{~b}$ ). Moreover a convective $\left(R_{h}\right)$ and a conduction term $\left(R_{c}\right)$ can be identified (Figure $4 \mathrm{c}$ ) and the relationship shown in Eq. 8 can be written.

$$
2 R_{B H E}=R_{h}+R_{c}
$$

Since the grout nodes are located somewhere in between the pipes and the borehole wall, at a certain diameter $D_{x}$, the conductive thermal resistance on equation 8, $R_{c}$, is divided into two different resistances (Figure 4d), following Eq. 9.

$$
\begin{gathered}
\qquad R_{c}=R_{b}+R_{x} \\
\text { where } R_{b}=R_{b 1}=R_{b 2}
\end{gathered}
$$

The parameters $R_{b 1}$ and $R_{b 2}$ from the thermal network (Figure 3) correspond to the parameter $R_{b}$ on Eq. 9. On the other hand, the thermal resistance $R_{g}$ of the $\mathrm{B} 2 \mathrm{G}$ model is determined adding the resistance between 
247

the grout nodes and the borehole wall $R_{x}$ to the ground thermal resistance $R_{b g}$ (Figure 4d), as shown in Eq. 10.

$$
R_{g}=R_{b g}+R_{x}
$$

The mean convection term $R_{h}$ is calculated assuming a mean value of the convective heat transfer coefficient $(h)$ inside the pipes (Eq. 11):

$$
R_{h}=\frac{1}{\pi D_{p, i} \mathrm{~d} z h}=\frac{1}{\pi \mathrm{d} z \mathrm{Nu} k}
$$

where $(N u)$ is the Nusselt number which can be calculated according to the appropriate correlation depending on the flow regime (e.g. [46]), and $D_{p, i}$ is the internal pipe diameter.

For the calculation of the conduction thermal resistance, an equivalent surface has been determined, which represents the pipes surface and allows to solve the heat transfer problem as a semi-cylindrical conductive heat transfer (Figure 5a). For the equivalent surface, the approach suggested by Pasquier et al. [30] has been used, giving the equivalent diameter shown in Eq. 12

$$
D_{e q}=D_{p, e} \sqrt{\frac{4 W}{\pi D_{p, e}}+1}
$$

Thus, the conduction thermal resistance for each borehole zone is calculated considering the conductive heat transfer in a semi-cylinder (Eqs. 13, 14):

$$
\begin{aligned}
R_{b} & =\frac{\ln \left(D_{x} / D_{e q}\right)}{\pi k_{b} \mathrm{~d} z} \\
R_{x} & =\frac{\ln \left(D_{b} / D_{x}\right)}{\pi k_{b} \mathrm{~d} z}
\end{aligned}
$$


where $D_{x}$ is the position of the borehole nodes, with $D_{e q}<D_{x}<D_{b}$ (Figure 5b).

As reported in Lamarche et al. [31], the position $D_{x}$ depends strictly on the internal borehole geometry, especially on the shank spacing and it is not possible to determine it a priori. Generally, if the shank spacing is high and, therefore, the pipes are quite close to the borehole wall, it is advisable to locate the nodes directly on the borehole diameter $\left(D_{x}=D_{b}\right)$. Otherwise, an approximation could be obtained by means of a sensitivity analysis on the effect of different $D_{x}$ comparing the numerical results with the experimental ones obtained in a step-test.

The thermal resistance between the pipe nodes $\left(R_{p p}\right)$ is quite complex to obtain due to the two-dimensional heat transfer phenomena occurring in this grouting zone. In order to simplify the calculation, the maximum value is assumed as a limit, considering a one-dimensional linear heat conduction between them (Figure 5r). Analogue to this, a one-dimensional heat transfer between the two borehole nodes is assumed $\left(R_{b b}\right)$ through the remaining surface, as shown in Figure $5 \mathrm{~d}$ :

$$
R_{p p}=\frac{W-D_{p, e}}{D_{p, e} \mathrm{~d} z k_{b}}
$$

$$
R_{b b}=\frac{W}{k_{b}\left(D_{b}-D_{p, e}\right) \mathrm{d} z}
$$

\subsubsection{Ground node}

The thermal capacitance of the ground, $C_{g}$, depends essentially on the penetration depth, $D_{g p}$, of the borehole. The penetration depth depends on the heat injection/extraction time and on the ground thermal properties and. In the B2G model, it becomes an adjusting parameter which depends 
a)

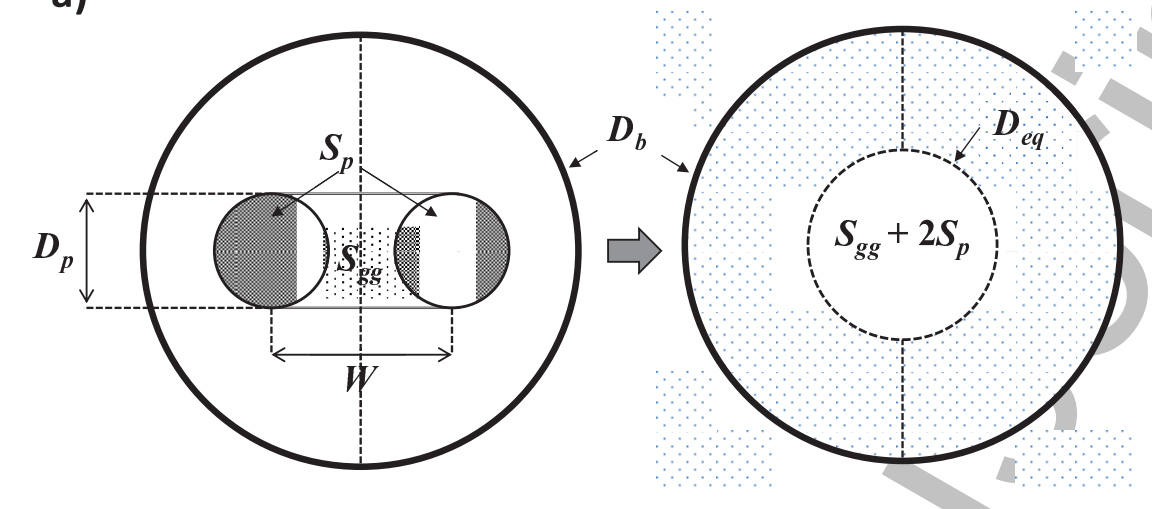

b)

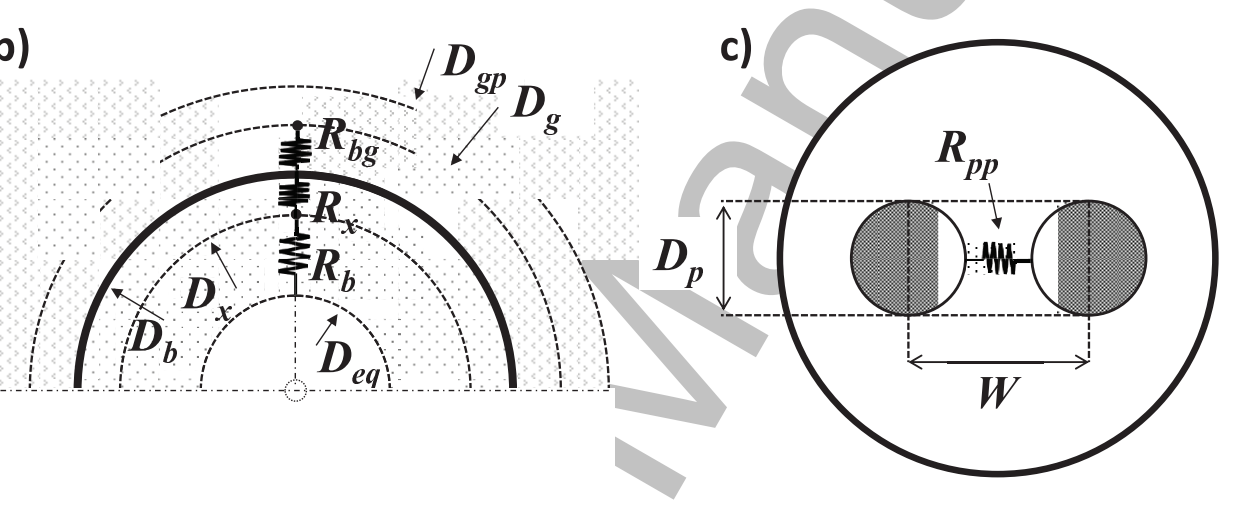

d)

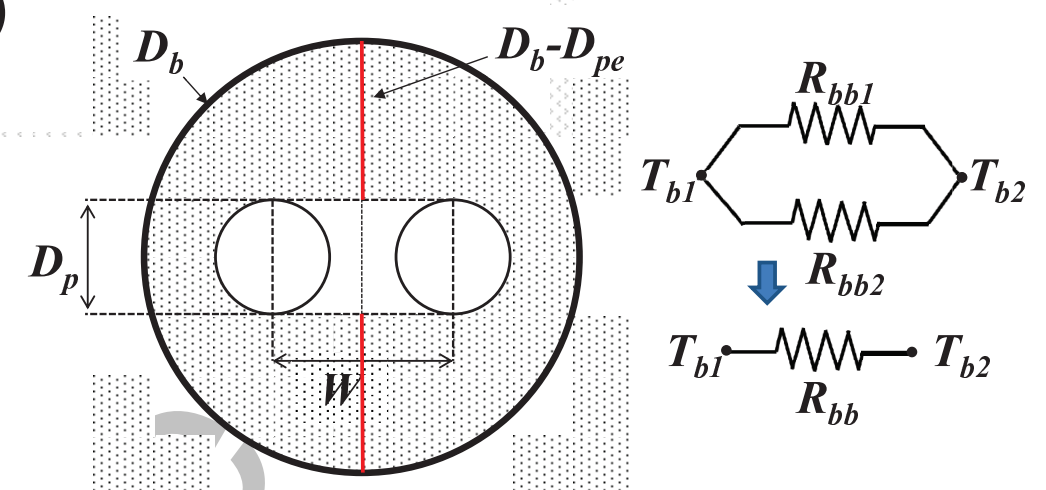

Figure 5: Geometrical model characteristics to calculate a) the equivalent diameter [30], b) borehole node position, c) pipe to pipe thermal resistance, d) borehole node to borehole node thermal resistance. 
on the simulation time considered. For a given penetration depth, it is possible to calculate directly the thermal capacitance, $C_{g}$, as follows:

$$
C_{g}=\frac{\pi}{4}\left(D_{g p}^{2}-D_{b}^{2}\right) c_{g} \mathrm{~d} z
$$

On the other hand, assuming that all the ground thermal capacitance is lumped in the diameter $D_{g}$, calculated as the average between the borehole diameter, $D_{b}$, and the penetration diameter, $D_{g p}$, the corresponding thermal resistance of the ground $R_{b g}$ is calculated with Equation 18 .

$$
R_{b g}=\frac{1}{\pi k_{g} \mathrm{~d} z} \ln \left(\frac{D_{g}}{D_{b}}\right)
$$

Finally, the thermal resistance $R_{g}$ in Eq. 3,5 can be calculated by means of Equation 19,

$$
R_{g}=R_{x}+R_{b g}
$$

\section{Model validation}

\subsection{GeoCool Plant}

GeoCool plant is a demonstration facility located at the Universitat Politècnica de València (UPVLC), Spain. It was built in the framework of a FP5 European project named 'GeoCool' project [45]. The system consists of a reversible ground source heat pump (GSHP) that provides the air conditioning for a set of spaces in the Department of Applied Thermodynamics at UPVLC (Figure 6). The heating nominal capacity of the heat pump is $17 \mathrm{~kW}$ (with water return temperatures of $35 \circ \mathrm{C}$ and $17 \circ \mathrm{C}$ ) and the cooling nominal capacity is $14.7 \mathrm{~kW}$ (with water return temperatures of $14 \circ \mathrm{C}$ and $25 \circ \mathrm{C})$. The total air conditioned area is approximately $250 \mathrm{~m}^{2}$. 


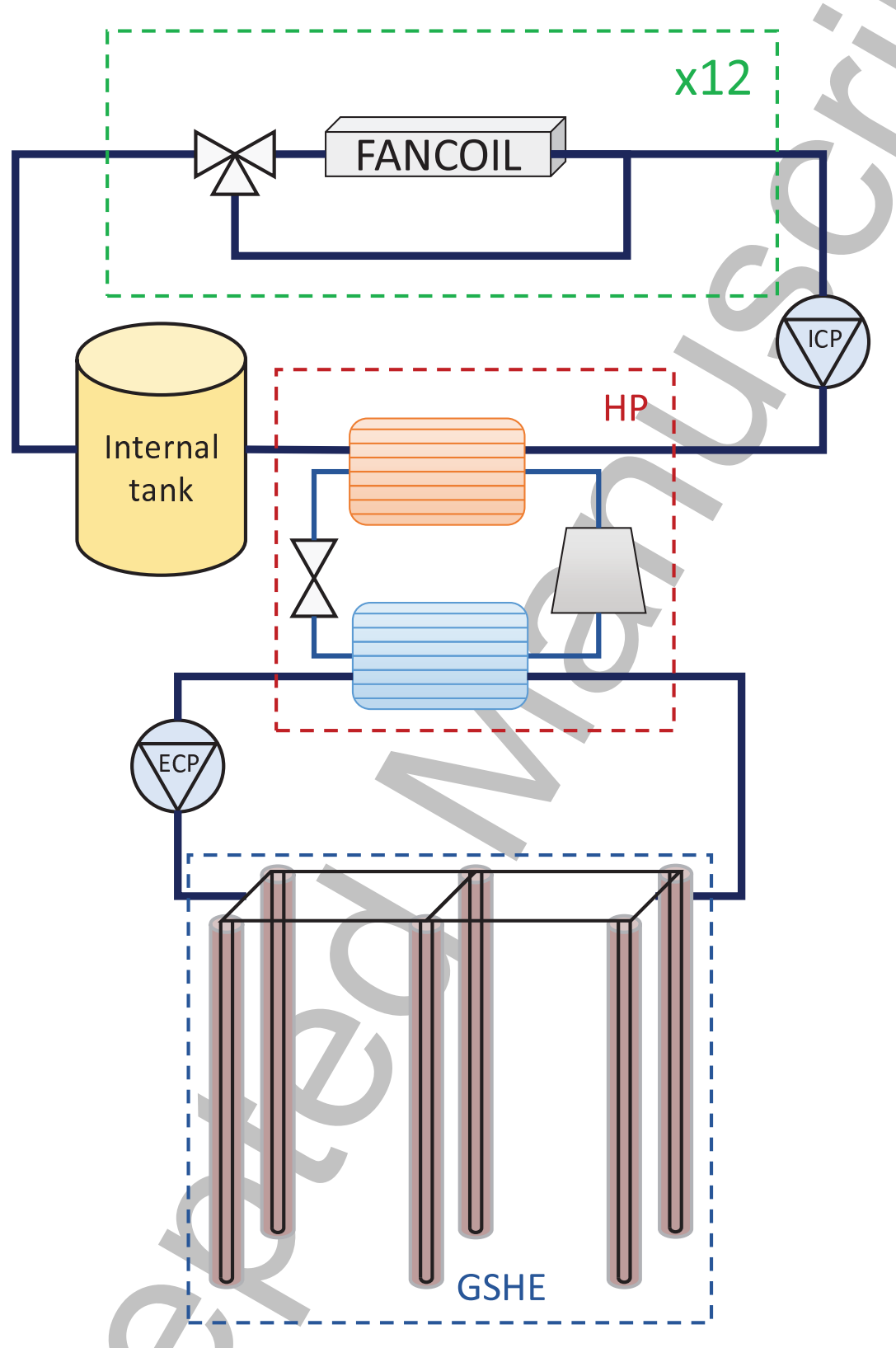

Figure 6: GeoCool schematic diagram with the internal and external circuits. 
A detailed description of the installation and the particular conditions of its operation is provided in [8]. In [47], the design and construction process of the installation was presented, including the design of the ground source heat exchanger (GSHE). Figure 6] shows the basic scheme of the installation. The reversible GSHP is connected to an external circuit and an internal circuit. The internal circuit includes a total of 12 parallel connected fancoils, an hydraulic loop for water distribution, a water storage tank and a circulation pump. On the other hand, the external circuit comprises the GSHE, a circulation pump, and the corresponding hydraulic loop.

The system has been working since February 2005, and it has been completely monitored during all its operation time. The installation is programmed to work 15 hours a day, five days per week, being switched off during the nights and the weekends. During its normal operation, the heat pump controller switches on/off the compressor depending on the controlled temperature. The external circulation pump switches on/off together with the heat pump, with a lag of one minute: it switches on one minute before the heat pump, and switches off one minute later. The internal circulation pump is continuously switched on during the 15 hours of operation of the system. A detailed description of the GSHE is provided in the section 3.1.1.

The on/off cycling of the heat pump and the external circulation pump results in a characteristic temperature evolution along the day. Figure 7 shows the evolution of the water temperatures entering and exiting the heat pump, for a typical heating and cooling day. The on/off cycles of the heat pump are reflected in the water temperatures, both in the internal and the external circuit, which periodically increase and decrease. Typical water temperatures entering the boreholes are around $30^{\circ} \mathrm{C}$ in cooling periods 
and $14^{\circ} \mathrm{C}$ in heating periods, while the exiting water temperatures from the $\mathrm{BHE}$ range from $25^{\circ} \mathrm{C}$ to $17^{\circ} \mathrm{C}$, respectively. A more detailed analysis of the water temperatures of the system and their evolution along the years can be found in [48].

The system performance has been monitored by a network of sensors that measures the temperature, mass flow, and power consumption. The temperature sensors are four-wire PT100 with accuracy $\pm 0.1 \mathrm{C}$. The mass flow meters are Danfoss Coriolli meters, model massflo MASS 6000 with signal converter Compact IP 67 and accuracy $<0.1 \%$. The power meters are multifunctional power meters from Gossen Metrawatt, model A2000 with accuracy $\pm 0.5 \%$ of the nominal value. Reference data sets obtained from the installation were published in [8].

\subsubsection{Ground Source Heat Exchanger}

The GSHE was designed according to the building demand, in order to minimize the impact of the installation on the ground thermal response. An analysis of the impact of the installation after the first five years of operation is presented in [48]. The analysis confirms the correct design of the installation, since the water return temperatures from the GSHE are nearly constant for each year.

The GSHE consists of 6 vertical boreholes, connected in parallel, and arranged in a 2 x 3 rectangular grid, with a $3 \mathrm{~m}$ spacing between boreholes. Each borehole has a nominal diameter of $150 \mathrm{~mm}$ and it is $50 \mathrm{~m}$ deep containing a single HDPE U-tube. The inner and external diameters of the U-tube are $25.4 \mathrm{~mm}$ and $32 \mathrm{~mm}$ respectively, with a center-to-center distance (shank spacing) of $70 \mathrm{~mm}$. All boreholes are filled with sand and 

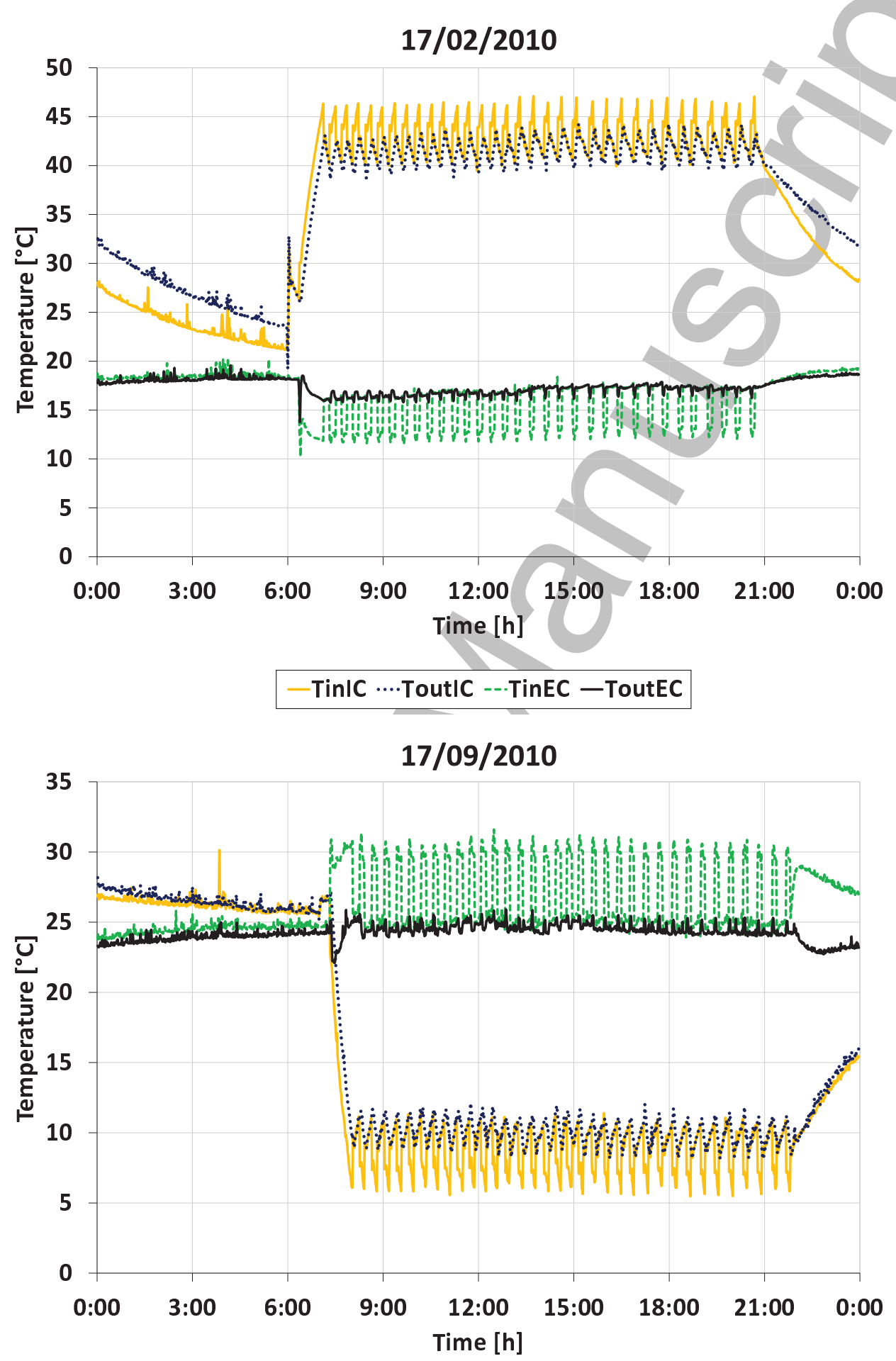

21

Figure 7: Evolution of the water temperatures at the internal and external circuit for a typical heating and cooling day $(17 / 02 / 2010-20 / 09 / 2010)$. 
sealed with bentonite on the top. Further details about the ground heat exchanger can be found in [47].

There are two temperature sensors located at the entrance and the exit of each borehole, measuring the water temperature at those points. Furthermore, there are several temperature sensors in 3 of the 6 boreholes, which are located at different depths between the upward and downward pipes.

Ground thermal properties were determined by means of laboratory analysis, using dry soil samples. For the thermal conductivity, a value of $1.43 \mathrm{~W} / \mathrm{mK}$ was obtained, although a high uncertainty (around 20\%) was observed. A value of $2.25 \mathrm{MJ} / \mathrm{m}^{3} \mathrm{~K}$ was obtained for the volumetric heat capacity. However, the groundwater level is about $3.5 \mathrm{~m}$. So, the effective values of the ground thermal conductivity and capacity could be significantly higher.

\subsection{TRNSYS simulation}

This section presents the validation of $\mathrm{B} 2 \mathrm{G}$ against experimental measurements of one of the six boreholes of the GeoCool plant [8]. For this purpose, B2G has been implemented in the TRNSYS software, creating a new TRNSYS type. The experimental measurements of mass flow rate and of inlet water temperature have been used as inputs for the model at each simulation time step (1 minute). Finally, the calculated outlet fluid temperature at the U-tube has been compared against the experimental measurements

The model has been validated considering two different operating conditions: a step-test in cooling mode (performed on 04/11/2013) and the 
standard operating condition in two different typical days, one for heating mode (15/02/2010) and one for cooling mode (15/09/2010). The following assumptions have been made:

- The thermophysical properties of the ground and the grout havebeen increased considering that, as already stated in section 3.1.1, the groundwater level is about $3.5 \mathrm{~m}$ and the effective values of the conductivity and the volumetric thermal capacitance could vary significantly.

- The equivalent diameter has been calculated using the approximation suggested by Pasquier et al. [30] (see section 2.1, Eq. 12).

- The studied borehole is provided with spacers that ensure a value of $70 \mathrm{~mm}$ for the shank spacing. However, considering that the U-tube is not fixed inside the borehole and, therefore, the centering is not guaranteed, the borehole nodes have been located on the borehole wall, as suggested by Lamarche et al. [31] for pipe positions close to the borehole wall.

- The thermal capacitance of the ground node, $C_{g}$, has been deducted in order to obtain a good correspondence at the end of the 24 hours of simulation, since this is the time interval that the model is intended to reproduce.

Table 1 shows the values of all the parameters of the TRNSYS type considered in the present work. These parameters correspond to the ones required by the $\mathrm{B} 2 \mathrm{G}$ model (note that thermal capacitances and resistances are node values and, in this form, they depend on the number of nodes adopted). 


\begin{tabular}{|c|c|c|}
\hline \multicolumn{3}{|c|}{ Thermophysical properties } \\
\hline Ground thermal conductivity & $k_{g}$ & $2.09 W m^{-1} K^{-1}$ \\
\hline Grout thermal conductivity & $k_{b}$ & $2.09 W^{-1} K^{-1}$ \\
\hline Ground volumetric thermal capacitance & $c_{g}$ & $3200 \mathrm{kJm}^{-3} K^{-1}$ \\
\hline Grout volumetric thermal capacitance & $c_{b}$ & $3200 \mathrm{kJm}^{-3} K^{-1}$ \\
\hline Ground thermal diffusivity & $\alpha_{g}$ & $0.002351 m^{2} h^{-1}$ \\
\hline \multicolumn{3}{|c|}{ Geometrical characteristics } \\
\hline Borehole diameter & $D_{b}$ & $\mathrm{~mm}$ \\
\hline External U-pipe diameter & $D_{p, e}$ & $32 \mathrm{~mm}$ \\
\hline Internal U-pipe diameter & $D_{p, i}$ & $25.4 \mathrm{~mm}$ \\
\hline Shank spacing (center-to-center) & $W$ & $70 \mathrm{~mm}$ \\
\hline Depth & $L$ & $50 \mathrm{~m}$ \\
\hline \multicolumn{3}{|c|}{ Model parameters } \\
\hline Number of nodes & $\mathrm{n}$ & 150 \\
\hline Borehole node thermal capacitance & $C_{b 1}-C_{b 2}$ & $17.56 J K^{-1}$ \\
\hline Ground node thermal capacitance & $C_{g}$ & $1200 J K^{-1}$ \\
\hline Borehole conductive thermal resistance & $R_{b 1}-R_{b 2}$ & $0.2738 K W^{-1}$ \\
\hline Pipe to pipe thermal resistance & $R_{p p}$ & $0.8525 K W^{-1}$ \\
\hline Borehole to borehole thermal resistance & $R_{b b}$ & $0.4257 K W^{-1}$ \\
\hline Borehole to ground thermal resistance & $R_{g}$ & $0.2772 K W^{-1}$ \\
\hline Equivalent pipes diameter & $D_{e q}$ & $45 \mathrm{~mm}$ \\
\hline Borehole node position & $D_{x}$ & $150 \mathrm{~mm}$ \\
\hline Ground radial penetration diameter & $D$ & $860 \mathrm{~mm}$ \\
\hline Ground nodes position & $D_{1}$ & $505 \mathrm{~mm}$ \\
\hline
\end{tabular}

Table 1: Main parameter adopted in the present work. 


\section{Results and discussion}

\subsection{Step-test}

Since the GeoCool plant performance is based on on/off cycles, adjusting and validating the model parameters with experimental data of a typical day becomes a difficult task. In order to obtain a suitable set of experimental data, a step-test was performed in the installation, on November 2013.

The test was carried out with the heat pump configured in cooling mode (condenser heat injected into the ground source heat exchanger). The main objective of the test was to obtain experimental data for a period of a few hours, with the heat pump continuously running in all the period, and with a thermal load approximately constant. For this purpose, the thermal load of the building was increased by means of electric heaters which were located in the air-conditioned offices, in order to increase the thermal demand of the building and avoid the cycling of the heat pump during the step test. Figure 8 shows the evolution of the water temperatures entering and exiting the ground loop during the test. The water temperatures presented in Figure 8 correspond to the inlet and outlet temperatures of the internal and external circuit, measured at the heat pump (TinIC, ToutIC, TinEC, ToutEC). The internal and external circuit mass flow rates are also presented in Figure 8 . Looking at the evolution of the water flow rate at the internal and external circuit, it is possible to know how the test was carried out.

- At 7:00 h the internal circulation pump was switched on, according to the schedule of the installation.

- At 10:00 $\mathrm{h}$ the test started, switching on the external circulation pump, but not the heat pump, and letting the water circulate without 25 
any thermal load being injected, so as to know the initial conditions for the water and the ground temperature. During this period of time, the internal circuit water temperatures increase, since the heat pump is switched off while the fancoils and the internal circulation pump are switched on.

- At 13:50 h the heat pump was switched on.

- At 20:55 h the internal circulation pump and the heat pump were switched off, according to the installation schedule. However, the external circulation pump was forced to remain switched on in order to produce a recovery step until 9:00 h of the next day, which was also useful for the model validation.

For model validation purposes, only the test period data are used, i.e. starting from 9:00 and for a total of 24 hours. The water temperature at the inlet of the borehole is used as input to the model. The simulated outlet water temperature is compared with the experimental one. Since equalizing valves have been installed in the BHE, the total mass flow rate is equally distributed between the six boreholes, thus the simulation flow rate for the model can be obtained dividing the total mass flow rate, experimentally measured, by six. Finally, using the parameters of Table 1, the simulation results of the model are shown in Figure 9.

As shown in Figure 9a, B2G correctly reproduces the evolution of the water temperature at the outlet of the borehole. The simulation results present a good agreement with the experimental ones with only a little deviation at around one hour after the starting of the test, reflecting that real results present a slightly higher inertia than the ones predicted by the 


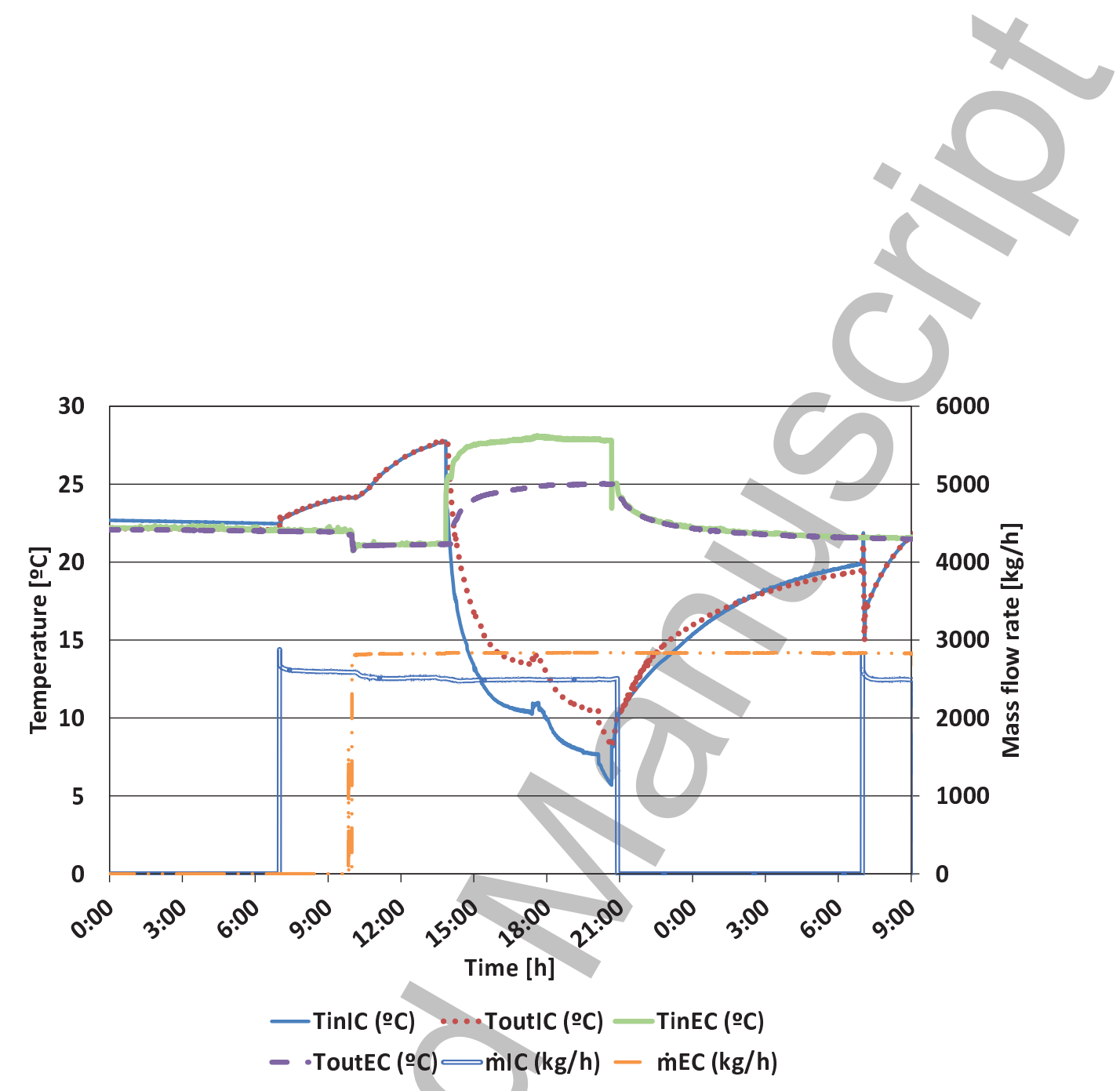

Figure 8: Step-test: water temperatures and flow rates at both sides of the heat pump. TinIC: internal circuit inlet temperature. ToutIC: internal circuit outlet temperature. TinEC: external circuit inlet temperature. ToutEC: external circuit outlet temperature. 

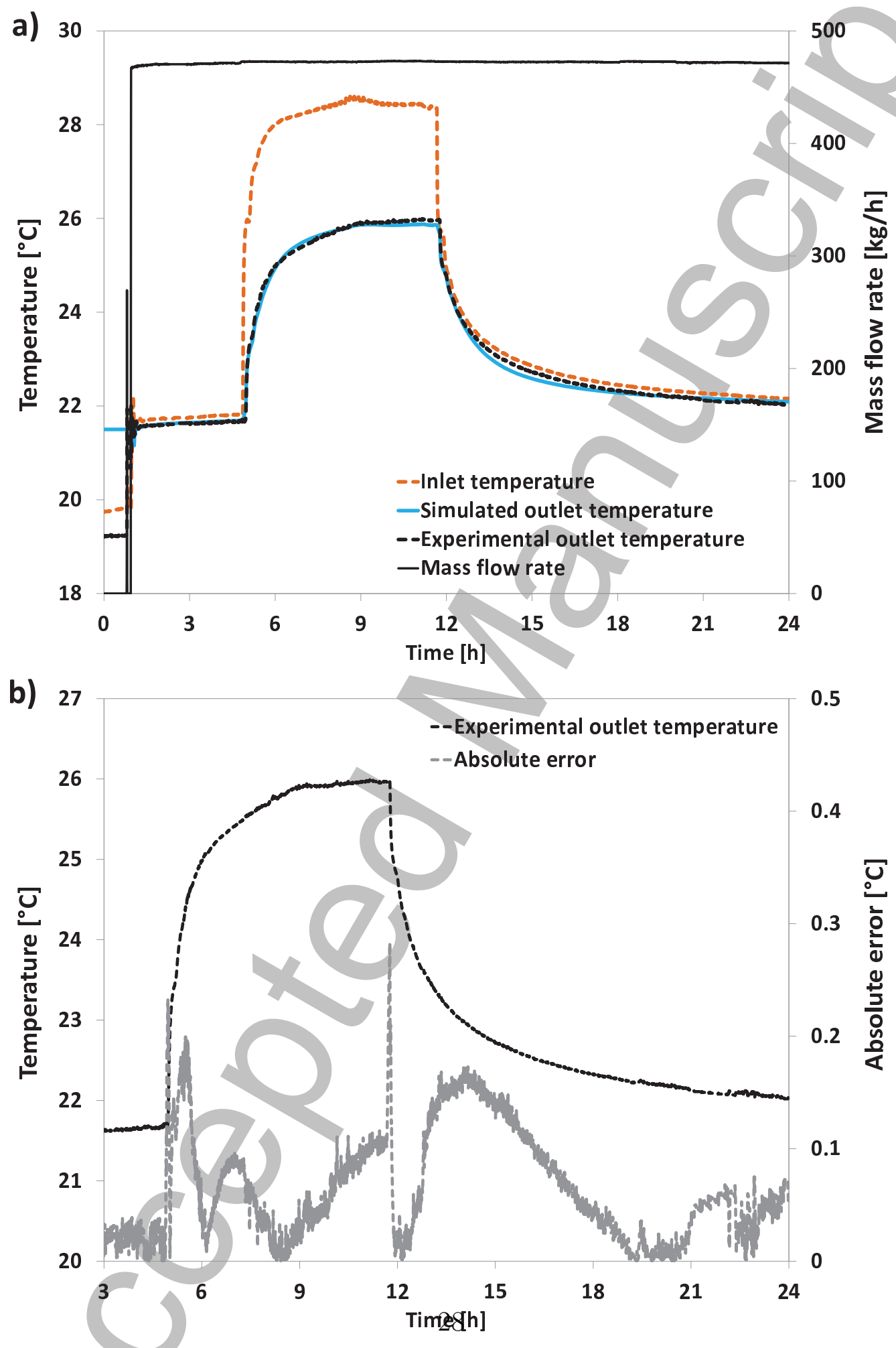

Figure 9: Step-test simulation result. a) Temperature and mass flow rate profiles. b) Absolute error between simulated and experimental outlet water temperature profiles. 
model. The same deviation can be observed in the recovery step. However, the medium-term results tend to the experimental data, even after 24 hours of simulation. Moreover, Figure 9b reports the correspondent absolute error between experimental and numerical results, showing that B2G is able to reproduce the outlet temperature profile with a maximum error of 0.3 $\mathrm{K}$ in correspondence of the injection pulse, where the dynamic effects are stronger. Therefore, it can be concluded that $\mathrm{B} 2 \mathrm{G}$ is able to reproduce the outlet water temperature evolution in the short-term with a high accuracy.

\subsection{1. $D_{x}$ analysis}

The previous results were obtained by assuming the borehole nodes to be located at the borehole wall $\left(D_{x}=D_{b}\right)$. This assumption must be checked with a sensitivity analysis of the position of the borehole nodes. The value of $D_{x}$ is calculated as shown in Eq. 20, considering that the borehole nodes have to be located somewhere in between $D_{e q}$ and $D_{b}$.

$$
D_{x}=a\left(D_{b}\right)+(1-a) D_{e q} \text { with } 0<a<1
$$

Figure 10 shows the comparison between the simulated outlet water temperature and the experimental one, for different values of $D_{x}$, corresponding to different values of the parameter $a(a=[1,0.9,0.8,0.7,0.6,0.5])$. As it can be observed in Figure 10a, differences between simulation results are negligible after a few hours. Differences in the short-term response are highlighted in Figure 10b which shows an amplified view of the first hours of the step.

Results show that situating the nodes at the borehole wall produces the best fitting. Therefore, the initial assumption made in this work is validated, also verifying the suggestion made by Lamarche et al. [31]. 
a)

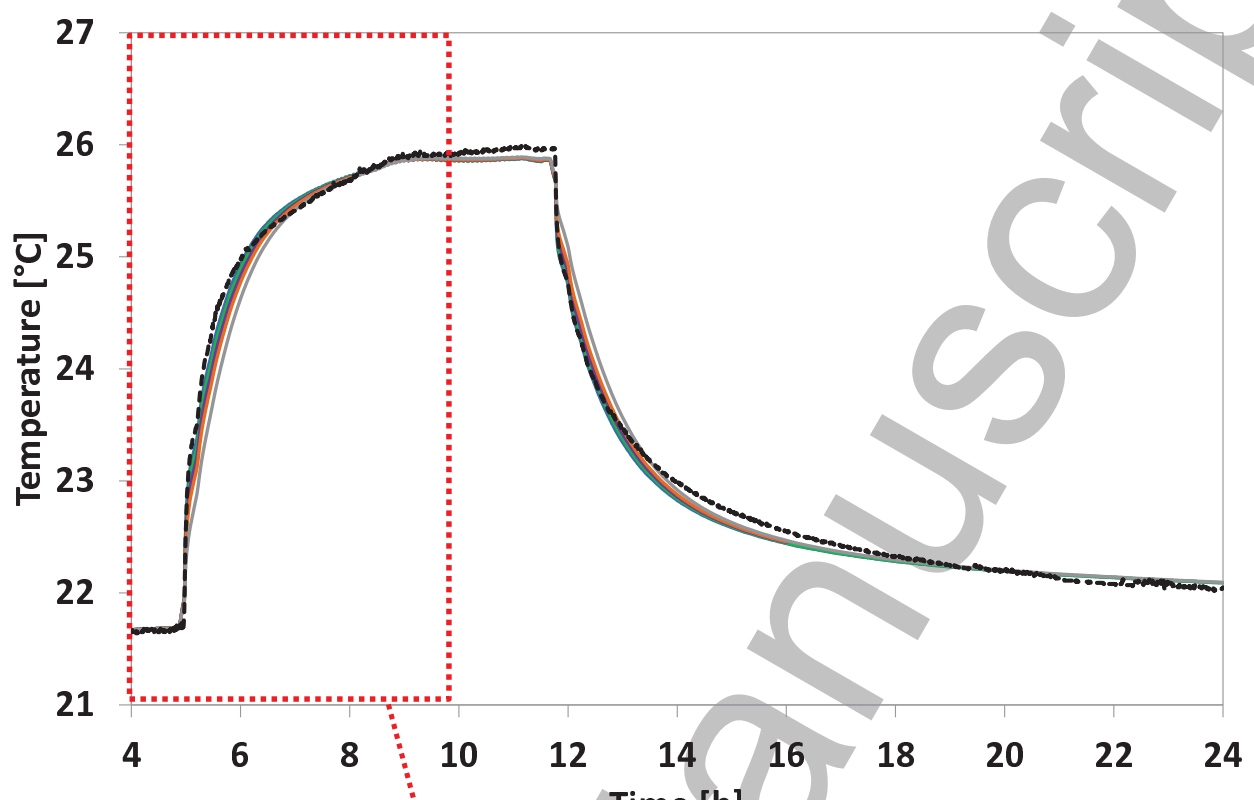

b)

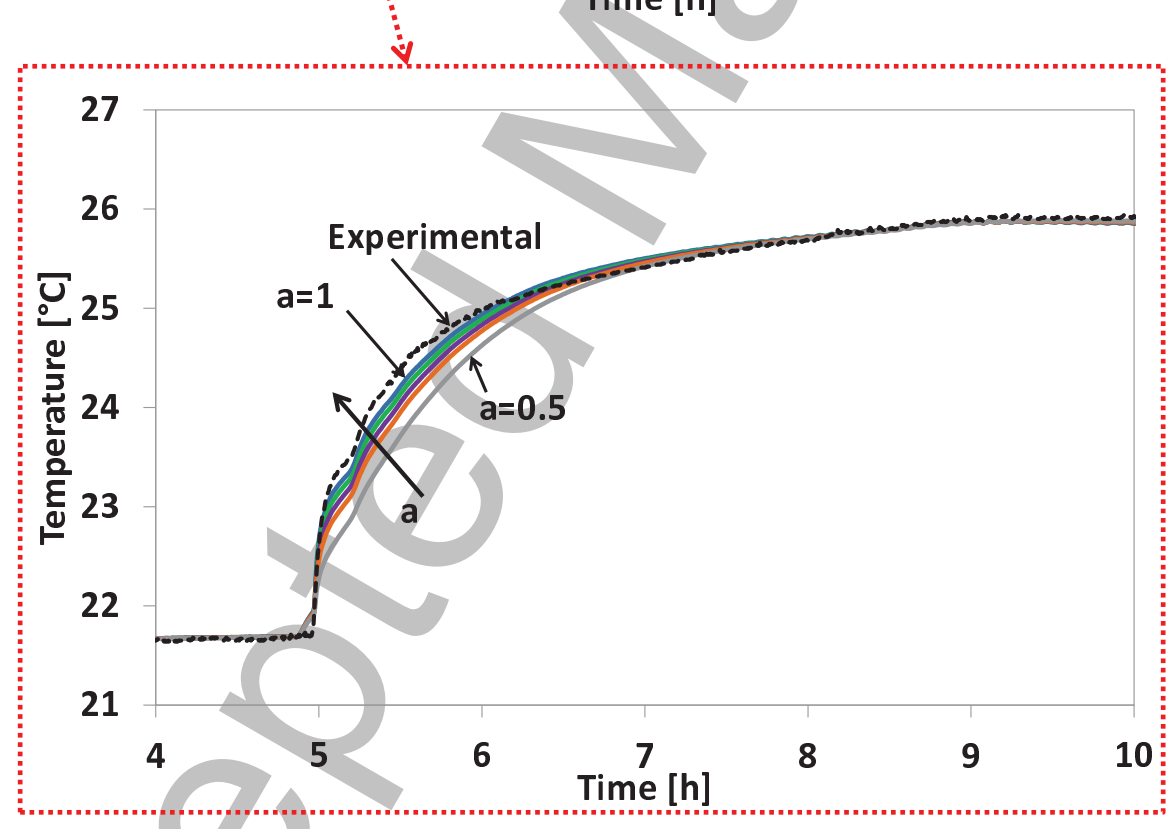

Figure 10: Step-test: sensitivity analysis of the position of the borehole nodes. 


\subsection{Typical day performance}

The model will be now double-validated against experimental data corresponding to the typical daily operation of GeoCool plant. The water temperature profiles for typical heating and cooling days have been presented in Figure 7. The water temperatures from the same borehole is used for simulation and validation of $\mathrm{B} 2 \mathrm{G}$ model. The results of the simulations for both heating and cooling days are shown in Figures 11 and 12, compared with the experimental results.

As in the previous section, the borehole inlet water temperature is employed as the input for the $\mathrm{B} 2 \mathrm{G}$ model, and the calculated outlet temperature is then compared with the experimental measurements. The initial temperature for the borehole model has been determined taking into account the first peak in the outlet temperature, that corresponds to the water inside the borehole during the night.

Figure 11b shows an augmented section of the borehole outlet water temperature shown in Figure [1]a, for heating mode, where the short-term response of the model can be analyzed. In order to better understand the simulation results, critical points (A-E) have been identified in Figure 11b.

During the OFF cycle, i.e. from A to B points of Figure 11b (see that the mass flow rate, also shown in Figure 11, is null during this period), the experimental temperature measured at the outlet of the borehole tends to the ambient temperature, which in winter means that it decreases during this period. Actually, since there is no water flow rate as the external circulation pump is switched off during these intervals, this behavior does not reflect the borehole thermal performance but it is more related with the ambient temperature, which has a greater influence on the top of the 


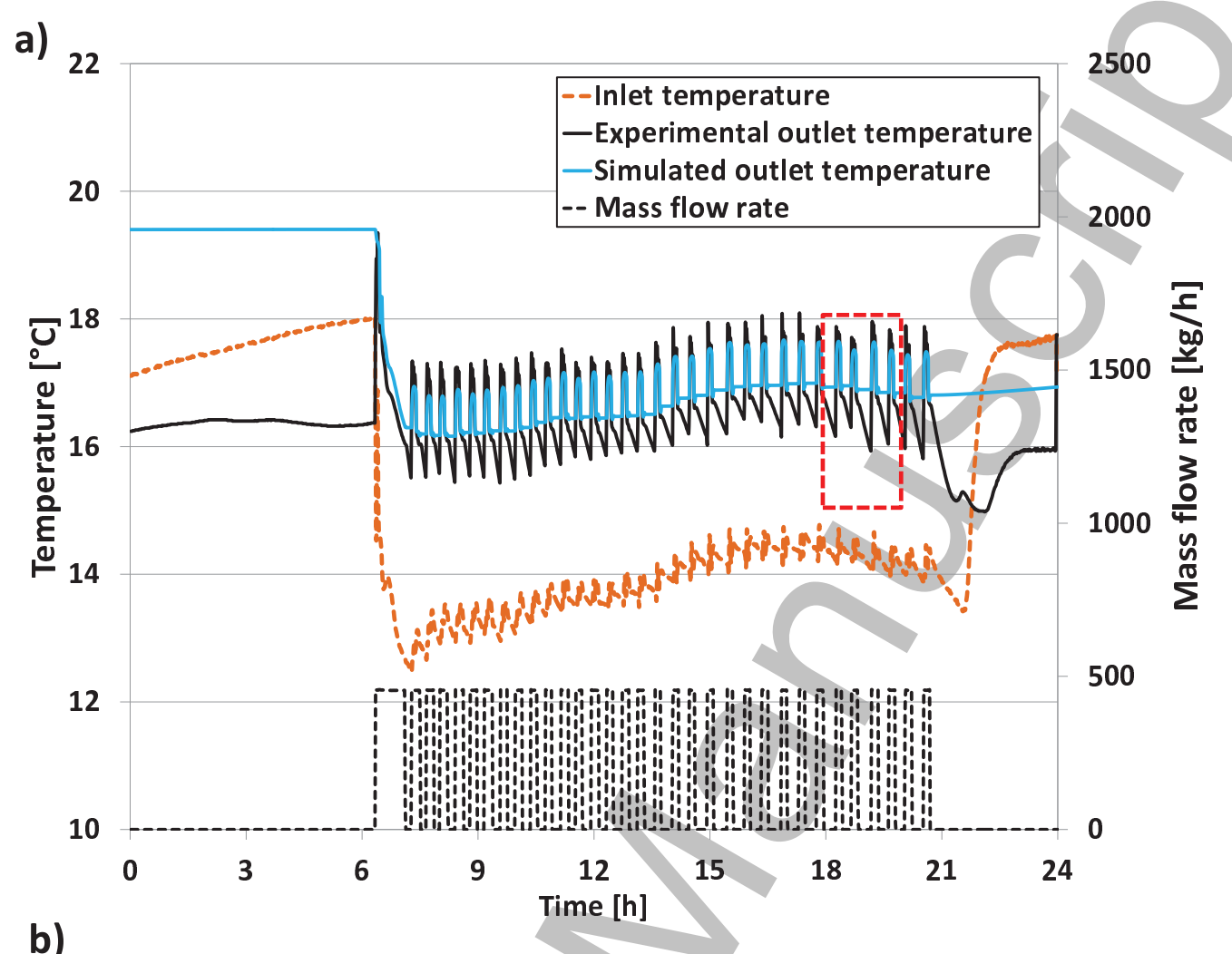

b)

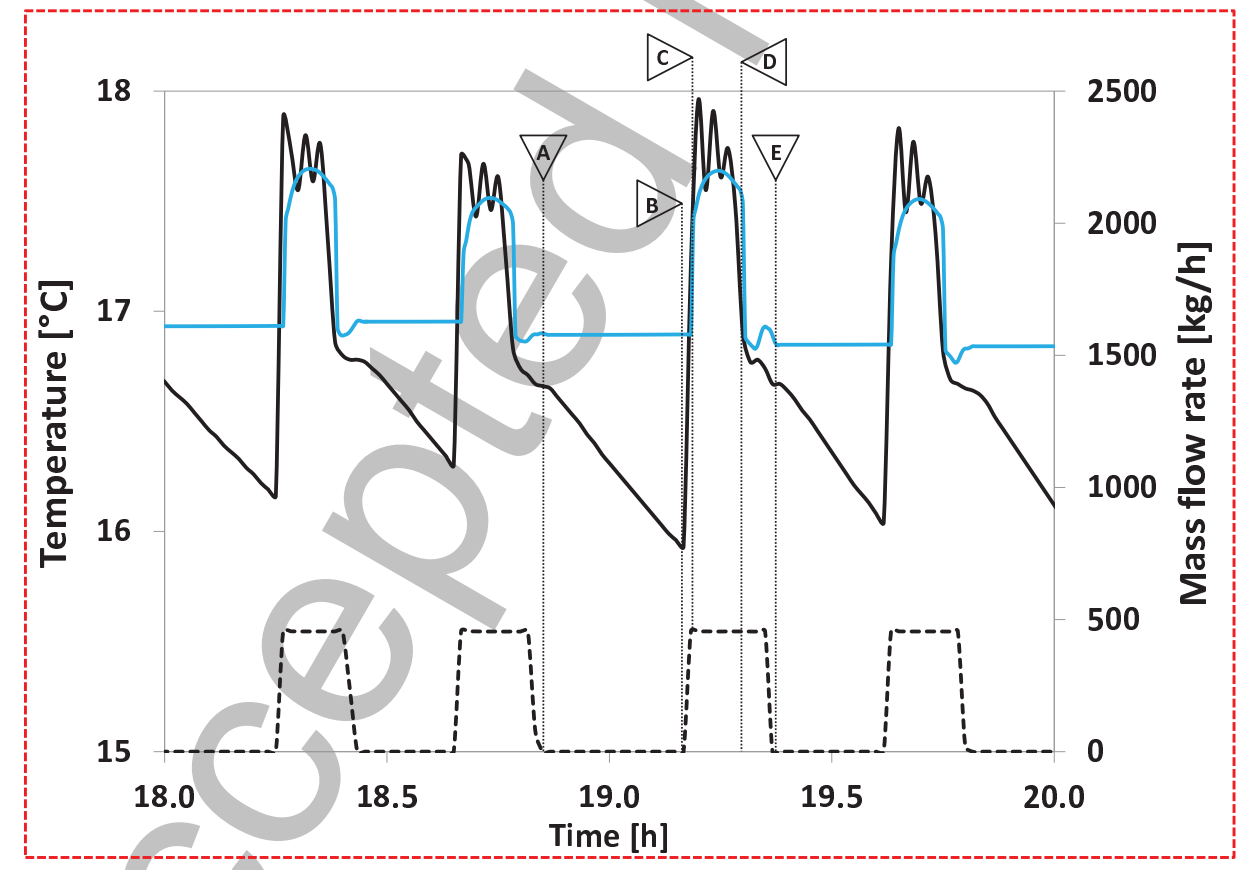

32

Figure 11: Typical heating day simulation results $(15 / 02 / 2010)$. 


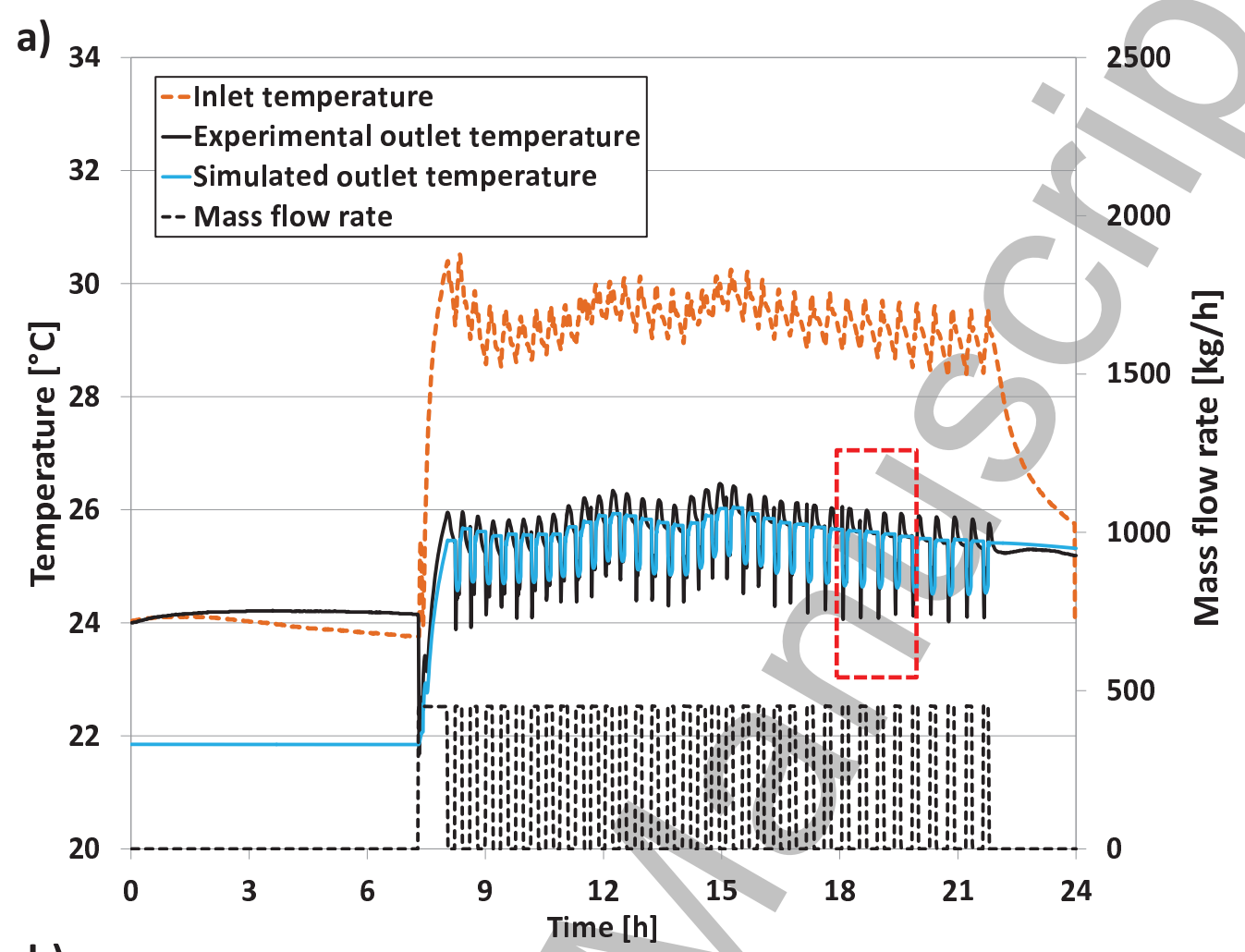

b)

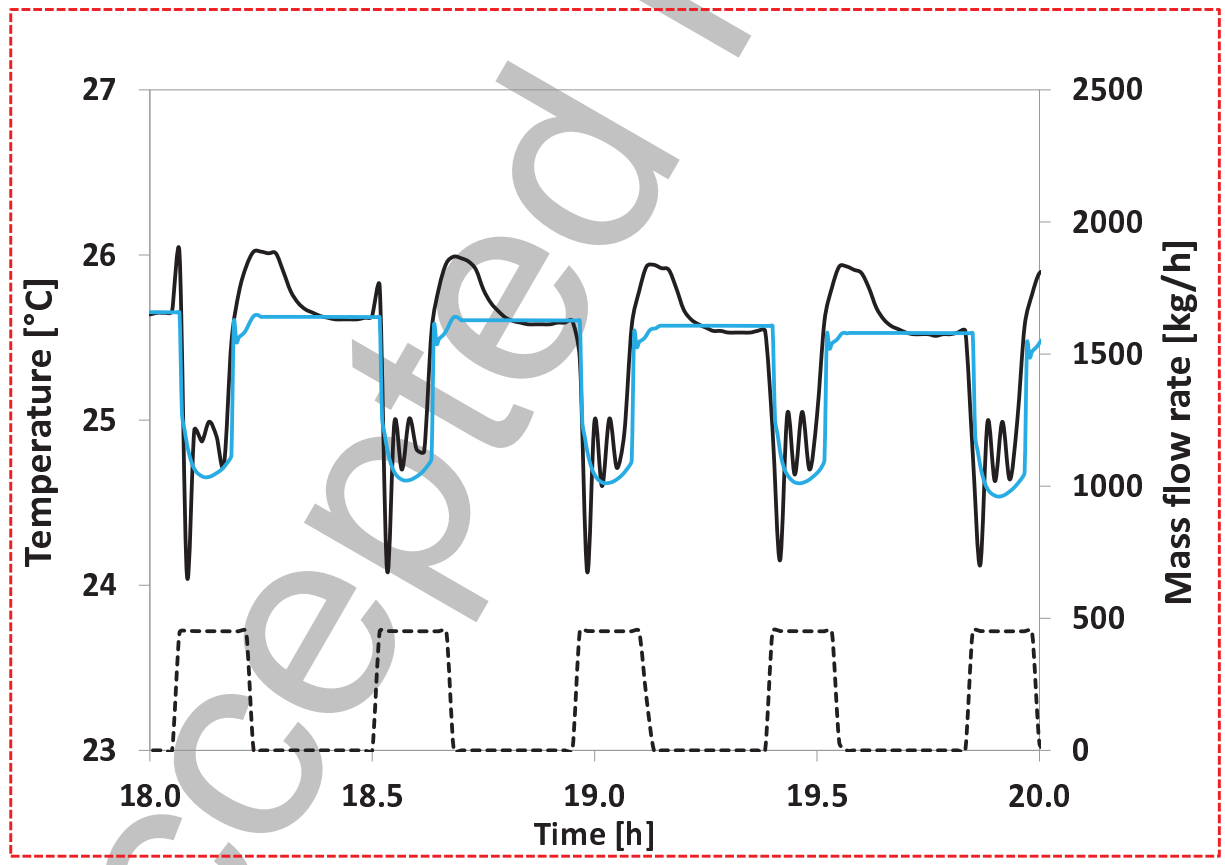

33

Figure 12: Typical cooling day simulation results $(15 / 09 / 2010)$. 
borehole, closer to the surface. However, the simulated temperature remains nearly constant during the OFF periods. This is due to the fact that the influence of the ambient temperature on the upper borehole nodes has not been taken into account, as it is out of the scope of the proposed model, since it happens out of the borehole. Besides, once the circulation pump switches on again (point B) and the water starts moving, the experimental water temperature suddenly increases (point $\mathrm{C}$ ), reaching the same values than the simulated one. It can be concluded, then, that the observed differences in the temperature evolution of the last borehole node during the OFF periods (between points $\mathrm{A}$ and $\mathrm{B}$ ) have no influence in the temperature evolution once the circulation pump is switched on, so, they must not be considered in the comparison.

At the start of the $\mathrm{ON}$ periods, from $\mathrm{B}$ to $\mathrm{C}$ points, the temperature suddenly increases. This is due to the displacement of the water that remains inside the borehole during the OFF period, whose temperature tends to the ground temperature. The water that enters in the borehole at the start of the ON period (point $\mathrm{C}$ ) takes some time (about 7 minutes) to travel through the U-tube, corresponding to the duration of the temperature peak, that is, from point $\mathrm{C}$ to $\mathrm{D}$ of Figure $11 \mathrm{~b}$. Once this water reaches the end of the borehole, a temperature decrease can be observed at the outlet temperature curve (point D). The predicted outlet temperature perfectly reproduces all these phenomena, achieving the main objective of the model: to correctly reproduce the short-term behavior of the borehole heat transfer and, therefore, of the outlet water temperature. The differences found in the shape of the experimental and simulated curves can be attributed to the temperature measurement uncertainty, and the vertical 
heat transfer effects which are neglected in the B2G model.

Taking a more general look at the temperature evolution during the day, it can be checked that the behavior observed in the step-test validation is reflected in this simulation. As expected, B2G simulation results for the water temperature evolution accurately reproduce the experimental ones, with almost negligible deviations after the first hour that reflect a slightly lower thermal inertia in the simulated results than in reality. At the end of the operating time, though, this difference is negligible.

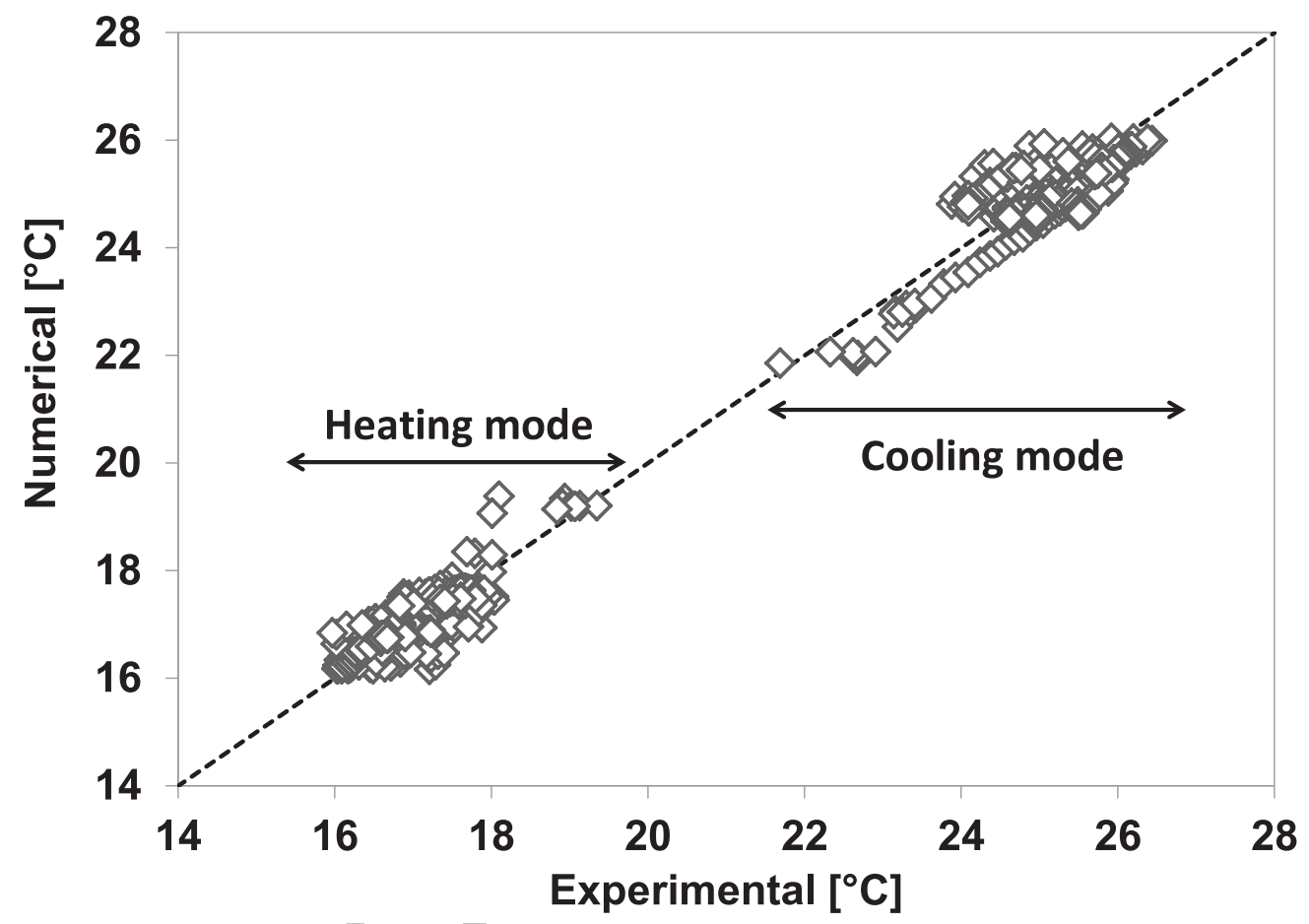

Figure 13: Experimental VS numerical outlet water temperature values for both heating and cooling cases.

The B2G response for cooling mode (Figure 12) presents the same evo- 
lution. Even if the temperature values are not so exactly adjusted, it can be considered that the $\mathrm{B} 2 \mathrm{G}$ behavior still represents the reality with enough accuracy, double-validating the proposed model.

Finally, Figure 13 reports the comparison between predicted and experimental outlet water temperature values for both heating and cooling cases. As it is possible to observe, $\mathrm{B} 2 \mathrm{G}$ is able to reproduce correctly the outlet water temperature despite the strong dynamic effects which occur during ON-OFF operating conditions.

\section{Conclusions}

Decoupling short-term and long-term responses allows the use of faster BHE models in both time scales, which can be combined lately to form a global model.

In this context, the B2G model is based on a thermal network approach, coupled with a vertical discretization of the borehole, focused on modelling the short-term response of a BHE. Several calculation techniques have been proposed in order to calculate the model parameters.

B2G was validated against experimental data from GeoCool plant, at Universitat Politècnica de València, Spain. Most of the parameters of the model could be estimated from a theoretical approach. The ones that remained as adjusting parameters have been adjusted using experimental data from a step-test performed at the installation without any other facility or machinery than the one already present at the system. So, the model can be easily adjusted to any installation by conducting a simple step-test similar to the one described in this work. 
The final validation of $\mathrm{B} 2 \mathrm{G}$ was performed considering standard operating conditions for two different days in heating and cooling mode. The results highlight that $\mathrm{B} 2 \mathrm{G}$ is able to reproduce the outlet water temperature profiles for all tested operating conditions, showing a good agreement with the experimental measurements.

\section{Acknowledgements}

The present work has been supported by the FP7 European project Advanced ground source heat pump systems for heating and cooling in Mediterranean climate (GROUND-MED). 


\begin{tabular}{|c|c|c|}
\hline \multicolumn{3}{|c|}{ Nomenclature } \\
\hline$\alpha$ & Thermal diffusivity $\left[\mathrm{m}^{2} / \mathrm{s}\right]$ & Subscript \\
\hline $\mathrm{BHE}$ & Borehole heat exchanger & 1 Downward pipe zone \\
\hline $\mathrm{c}$ & Volumetric thermal capacity $\left[\mathrm{J} / \mathrm{m}^{3} \mathrm{~K}\right]$ & 2 Upward pipe zone \\
\hline $\mathrm{C}$ & Thermal capacitance $[\mathrm{J} / \mathrm{K}]$ & b borehole \\
\hline $\mathrm{D}$ & diameter $[\mathrm{m}]$ & bb borehole node to borehole node \\
\hline GSHE & Ground source heat exchanger & c conduction \\
\hline GSHP & Ground source heat pump & external \\
\hline $\mathrm{k}$ & conductivity $[\mathrm{W} / \mathrm{mK}]$ & EC External circuit (ground loop) \\
\hline $\mathrm{h}$ & convective heat transfer coefficient $\left[\mathrm{W} / \mathrm{m}^{2} \mathrm{~K}\right]$ & eq equivalent \\
\hline $\mathrm{L}$ & $\operatorname{depth}[\mathrm{m}]$ & ground \\
\hline$\dot{m}$ & Mass flow rate $[\mathrm{kg} / \mathrm{h}]$ & gp ground penetration \\
\hline $\mathrm{n}$ & number of nodes [-] & j j-node \\
\hline $\mathrm{Nu}$ & Nusselt number [-] & $\mathrm{h}$ convection \\
\hline $\mathrm{r}$ & radius $[\mathrm{m}]$ & i internal \\
\hline $\mathrm{R}$ & Thermal resistance $[\mathrm{K} / \mathrm{W}]$ & IC Internal circuit (building) \\
\hline $\mathrm{R}_{B H E}$ & Borehole thermal resistance $[\mathrm{mK} / \mathrm{W}]$ & in Inlet \\
\hline $\mathrm{R}_{12}$ & Fluid to fluid thermal resistance $[\mathrm{mK} / \mathrm{W}]$ & $\mathrm{p}$ pipe \\
\hline $\mathrm{S}$ & surface $\left[\mathrm{m}^{2}\right]$ & pp pipe node to pipe node \\
\hline $\mathrm{t}$ & Time $[\mathrm{s}]$ & out Outlet \\
\hline $\mathrm{T}$ & Temperature $[\mathrm{C}]$ & $\mathrm{x}$ borehole node position \\
\hline $\mathrm{v}$ & velocity $[\mathrm{m} / \mathrm{s}]$ & \\
\hline $\mathrm{W}$ & shank spacing $[\mathrm{m}$ & \\
\hline $\mathrm{z}$ & Borehole depth coordinate $[\mathrm{m}]$ & \\
\hline
\end{tabular}




\section{References}

[1] Environmental Protection Agency: http://www.epa.gov/region1/eco/energy/re_geothermal.html, 14/03/2013.

[2] Hepbasli A, Akdemir O, Hancioglu E. Experimental study of a closed loop vertical ground source heat pump system. Energ Convers Manage 2003;44:527-48.

[3] Li M, Lai ACK. Thermodynamic optimization of ground heat exchangers with single U-tube by entropy generation minimization method. Energ Convers Manage 2013;65:133-9.

[4] Kizilkan O, Dincer I. Borehole thermal energy storage system for heating applications: Thermodynamic performance assessment. Energ Convers Manage 2015;90:5361.

[5] Kurevija T, Vulin D, Krapec V. Effect of borehole array geometry and thermal interferences on geothermal heat pump system. Energ Convers Manage 2012;60:13442.

[6] Zhang C, Chen P, Liu Y, Sun S, Peng D. An improved evaluation method for thermal performance of borehole heat exchanger. Renew Energ 2015;77:142-51.

[7] Shirazi AS, Bernier M. Thermal capacity effects in borehole ground heat exchangers. Energ Buil 2013;67:352-64.

[8] Ruiz-Calvo F, Montagud C. Reference data sets for validating GSHP system models and analyzing performance parameters based on a five-year operation period. Geothermics 2014;51:417-428.

[9] Wu W, You T, Wang B, Shi W, Li X. Evaluation of ground source absorption heat pumps combined with borehole free cooling. Energ Convers Manage 2014;79:334-43.

[10] Yoon S, Lee SR, Go GH. A numerical and experimental approach to the estimation of borehole thermal resistance in ground heat exchangers. Energy 2014;71:547-55.

[11] Ruiz-Calvo F, De Rosa M, Acuña J, Corberán JM, Montagud C. Experimental validation of a short-term Borehole-to-Ground (B2G) dynamic model. Appl Energ 2015;140:210-23.

[12] Monzó P, Mogensen P, Acuña J, Ruiz-Calvo F, Montagud C. A novel numerical approach for imposing a temperature boundary condition at the borehole wall in borehole fields. Geothermics 2015;56:35-44. 
[13] Self SJ, Reddy BV, Rosen MA. Geothermal heat pump systems: Status review and comparison with other heating options. Appl Energ 2013;101:341-8.

[14] Yang H, Cui P, Fang Z. Vertical-borehole ground-coupled heat pumps: A review of models and systems. Appl Energ 2010;87:16-27.

[15] Eskilson P. Thermal analysis of heat extraction boreholes. PhD Thesis, University of Lund, Sweden; 1987.

[16] Michopoulos A, Kyriakis N. Predicting the fluid temperature at the exit of the vertical ground het exchangers. Appl Energ 2009;86:2065-70

[17] Yavuzturk C, Spitler JD. A Short Time Step Response Factor Model for Vertical Ground Loop Heat Exchangers. ASHRAE Trans 1999;105(2):475-85.

[18] Spitler JD.GLHEPRO - A Design Tool For Commercial Building Ground Loop Heat Exchangers. Proceedings of the Fourth International Heat Pumps in Cold Climates Conference, Aylmer, Qubec. August 17-18; 2000.

[19] Hellström G, Sanner B. Earth energy designer: software for dimensioning of deep boreholes for heat extraction. Sweden: Department of Mathematical Physics, Lund University; 1994.

[20] Acuña J, Fossa M, Monzó P, Palm B. Numerically Generated g-functions for Ground Coupled Heat Pump Applications. Proceedings of the 2012 COMSOL Conference; 2012.

[21] Deerman JD, Kavanaugh SP.Simulation of vertical U-tube ground coupled heat pump systems using the cylindrical heat source solution. ASHRAE Trans 1991;97:287-95

[22] Kavanaugh SP, Rafferty K. Ground-Source Heat Pumps Design of Geothermal System for Commercial and Institutional Buildings. ASHRAE, Atlanta, 1997.

[23] ASHRAE Handbook-HVAC Applications, Geothermal Energy. 2003 (Chapter 32).

[24] Fossa M. The temperature penalty approach to the design of borehole heat exchangers for heat pump applications. Energ Build 2011;43:1473-9.

[25] Koohi-Fayegh S, Rosen MA. An analytical approach to evaluating the effect of thermal interaction of geothermal heat exchangers on ground heat pump efficiency. Energ Convers Manage 2014;78:184-92.

[26] Zarrella A, Scarpa M, De Carli M Short time-step analysis of vertical ground-coupled 
heat exchangers: The approach of CaRM. Renew Energ 2011;36:2357-67.

[27] Eskilson P, Claesson J. Simulation model for thermally interacting heat extraction boreholes. Num Heat Transf 1988;13:149-65.

[28] Bauer D, Heidemann W, Müller-Steinhagen H, Diersch HJG. Thermal resistance and capacity models for borehole heat exchangers.Int J Energ Res 2011;35:31220.

[29] Bauer D, Heidemann W, Diersch HJG. Transient 3D analysis of borehole heat exchanger modeling. Geothermics 2011;40:250-60.

[30] Pasquier P, Marcotte D. Short-term simulation of ground heat exchanger with an improved TRCM. Renew Energ 2012;46:92-9.

[31] Lamarche L, Kajl S, Beauchamp B. A review of methods to evaluate borehole thermal resistances in geothermal heat-pump systems. Geothermics 2010;39:187-200.

[32] Sharqawy MH, Mokheimer EM, Badr HM. Effective pipe-to-borehole thermal resistance for vertical ground heat exchangers. Geothermics 2009;38:271-77.

[33] Diersch HJG, Bauer D, Heidemann W, Rühaak W, Schätzl P. Finite element modeling of borehole heat exchanger systems Part 1: Fundamentals. Computers \& Geosciences 2011;37:1122-35.

[34] Diersch HJG, Bauer D, Heidemann W, Rühaak W, Schätzl P. Finite element modeling of borehole heat exchanger systems Part 2. Numerical simulation. Computers \& Geosciences 2011;37:1136-47.

[35] Esen H, Inalli M, Esen Y. Temperature distributions in boreholes of a vertical ground-coupled heat pump system. Renew Energ 2009;34:2672-9.

[36] Lee CK, Lam HN. Computer simulation of borehole ground heat exchangers for geothermal heat pump systems. Renew Energ 2008;33:1286-96.

[37] Zarrella A, Scarpa M, De Carli M. Short time-step performances of coaxial and double U-tube borehole heat exchangers: Modeling and measurements. HVAC\&R Research 2011;17(6):959-76.

[38] Yang W, Shi M, Liu G, Chen Z. A two-region simulation model of vertical U-tube ground heat exchanger and its experimental verification. Appl Energ 2009;86:200512.

[39] Oppelt T, Riehl I, Gross U. Modelling of the borehole filling of double U-pipe heat exchangers. Geothermics 2010;39:270-6. 
[40] Esen H, Inalli M. Modelling of a vertical ground coupled heat pump system by using artificial neural networks. Expert Systems with Applications 2009;36:10229-38.

[41] Montagud C, Corberán JM, Ruiz-Calvo F. Experimental and modeling analysis of a ground source heat pump system. Appl Energ 2013;109:328-36.

[42] University of Wisconsin-Madison. A TRaNsient SYtems Simulation program. http://sel.me.wisc.edu/trnsys/ [accessed 24/02/2014].

[43] De Rosa M, Ruiz-Calvo F, Corbern JM, Montagud C, Tagliafico LA. Borehole modelling: a comparison between a steady-state model and a novel dynamic model in a real ON/OFF GSHP operation. Journal of Physics: Conference Series 2014;547:012008.

[44] Hellström G. Duct Ground Heat Storage. Manual for Computer Code. 1989. Department of Mathematical Physics, University of Lund.

[45] GeoCool project (EU 5th Framework Programme, NNE5-2001-00847), http://cordis.europa.eu/projects/rcn/86940_en.html

[46] Gnielinsky V. New equations for heat and mass transfer in turbulent pipe and channel flow. International Chemical Engineering 1976;16:359-68.

[47] Magraner T. Validación Experimental de los Métodos de Diseño de Instalaciones de Bomba de Calor Acoplada al Terreno. PhD thesis, UPVLC; 2010.

[48] Montagud C, Corberán JM, Montero Á, Urchueguía JF. Analysis of the energy performance of a Ground Source Heat Pump system after five years of operation. Energ Buildings 2011;43:3618-26. 